\title{
WestVirginiaUniversity
}

THE RESEARCH REPOSITORY @ WVU

Graduate Theses, Dissertations, and Problem Reports

2013

\section{An Evaluation of School Zone Traffic Control Strategies}

Karly R. Hamric

West Virginia University

Follow this and additional works at: https://researchrepository.wvu.edu/etd

\section{Recommended Citation}

Hamric, Karly R., "An Evaluation of School Zone Traffic Control Strategies" (2013). Graduate Theses, Dissertations, and Problem Reports. 160.

https://researchrepository.wvu.edu/etd/160

This Thesis is protected by copyright and/or related rights. It has been brought to you by the The Research Repository @ WVU with permission from the rights-holder(s). You are free to use this Thesis in any way that is permitted by the copyright and related rights legislation that applies to your use. For other uses you must obtain permission from the rights-holder(s) directly, unless additional rights are indicated by a Creative Commons license in the record and/ or on the work itself. This Thesis has been accepted for inclusion in WVU Graduate Theses, Dissertations, and Problem Reports collection by an authorized administrator of The Research Repository @ WVU. For more information, please contact researchrepository@mail.wvu.edu. 


\title{
An Evaluation of School Zone Traffic Control Strategies
}

\author{
Karly R. Hamric
}

Thesis submitted to the

Benjamin M. Statler College of Engineering and Mineral Resources

at West Virginia University

in partial fulfillment of the requirements for the degree of

\author{
Master of Science \\ in \\ Civil Engineering
}

\author{
David R. Martinelli, Ph.D., Chair \\ Avinash Unnikrishnan, Ph.D. \\ Michael Pumphrey \\ Department of Civil and Environmental Engineering
}

Morgantown, West Virginia

2013

Keywords: School zone; Speed; Safety; Efficiency

Copyright 2013 Karly R. Hamric 


\section{ABSTRACT \\ An Evaluation of School Zone Traffic Control Strategies}

\section{Karly R. Hamric}

Throughout the past six decades, the predominant mode of student transport has shifted from walking to riding in a school bus or personal vehicle which has impacted both the safety and efficiency of school zone traffic control strategies. In order to improve school zone operations in West Virginia, current warrants and laws relevant to school zones within West Virginia and other states are researched. Concerns are characterized with respect to traffic efficiency and safety parameters and are addressed in a survey polling county and district transportation officials throughout West Virginia. In addition, school zone crash data provided by the Highway Safety Information System (HSIS) is analyzed for Ohio and North Carolina to gain a better understanding of the cause and nature of school zone crashes. Through multidisciplinary cooperation, school zone traffic control strategies should implement uniform procedures that target driver awareness and education on their actions and the effect they have on safety and efficiency and how the two issues are interrelated. 
This research project is sponsored by the U.S. Department of Transportation, Federal Highway Administration, and the West Virginia Department of Transportation, Division of Highways. It was completed with the assistance of many individuals and organizations. The Principal Investigators wish to express thanks to those identified below, as well as all of the other individuals and organizations that supported the project.

The support provided by the West Virginia Division of Highways is appreciated. Mr. Donald Williams deserves special thanks for providing data and contacts and for reviewing work. 


\section{Contents}

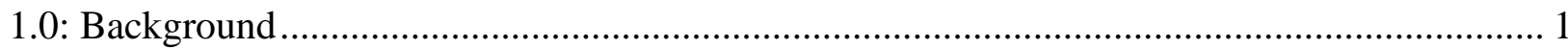

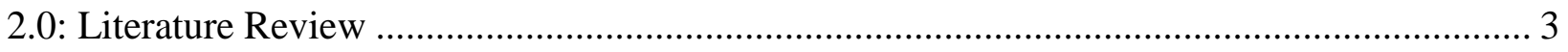

2.1: Vehicle Speeds in School Zones ....................................................................... 5

2.1.1: Driver Perception and Behavior ............................................................................. 7

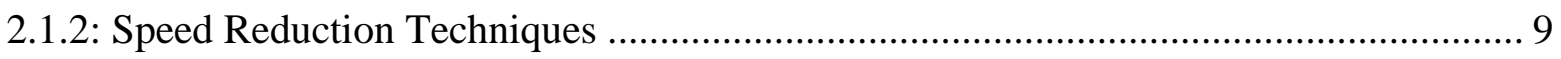

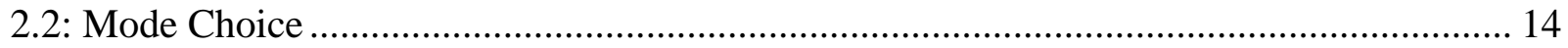

2.2.1: Barriers Preventing Children from Walking to School ........................................ 16

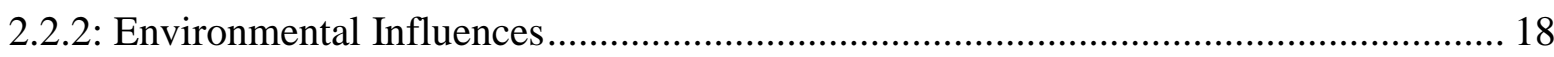

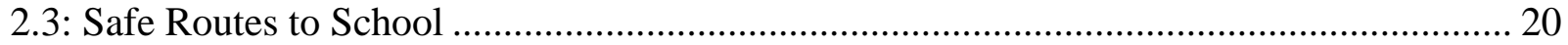

2.3.1: Successful Implementation...................................................................................... 22

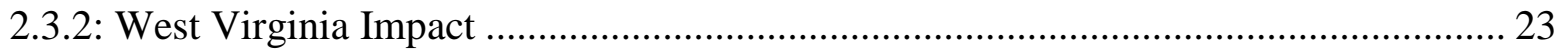

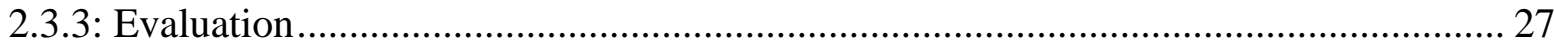

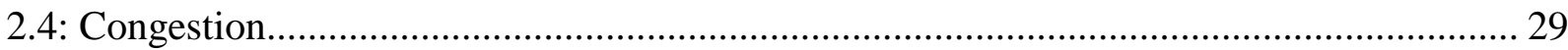

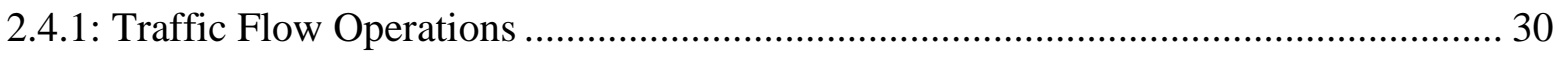

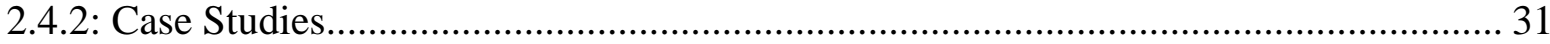

2.5: West Virginia School Zones ............................................................................... 36

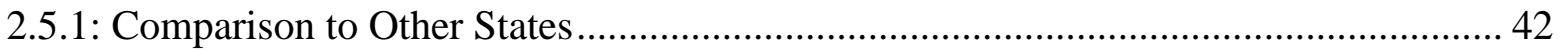

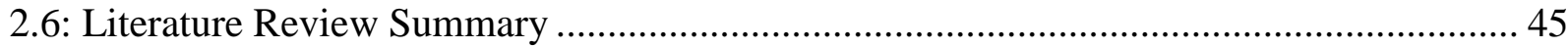

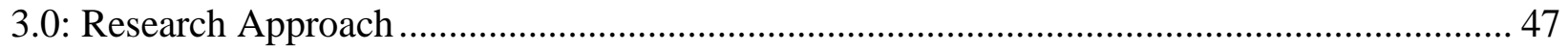

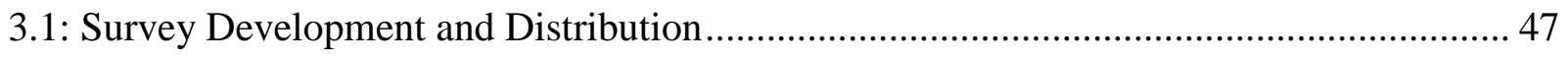

3.2: Highway Safety Information System Data .............................................................. 49

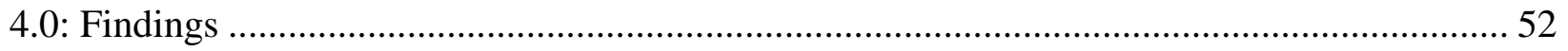

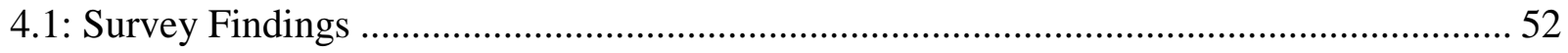

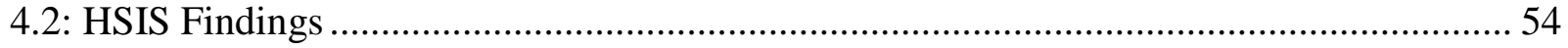

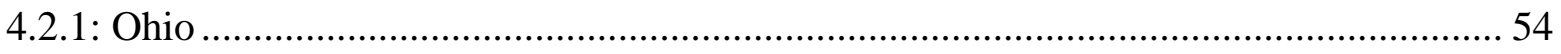

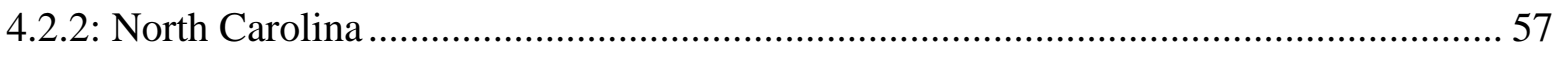

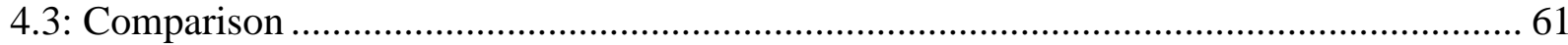

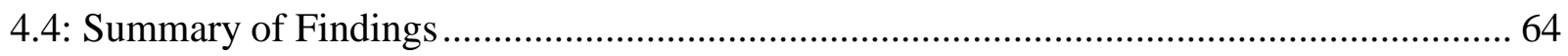

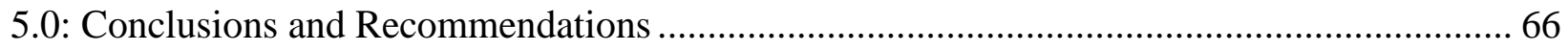

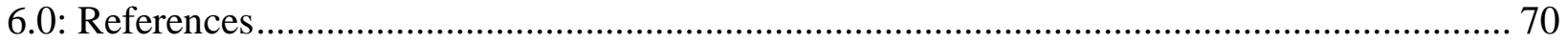




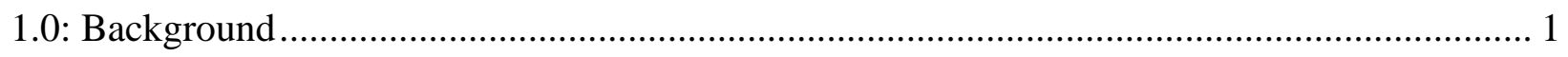

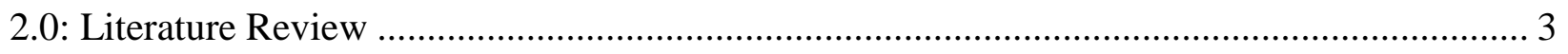

2.1: Vehicle Speeds in School Zones ................................................................................ 5

2.1.1: Driver Perception and Behavior .............................................................................. 7

2.1.2: Speed Reduction Techniques ............................................................................... 9

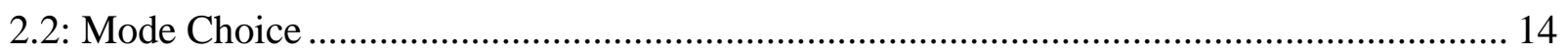

2.2.1: Barriers Preventing Children from Walking to School ............................................. 16

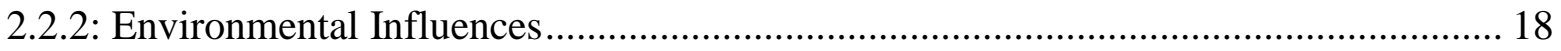

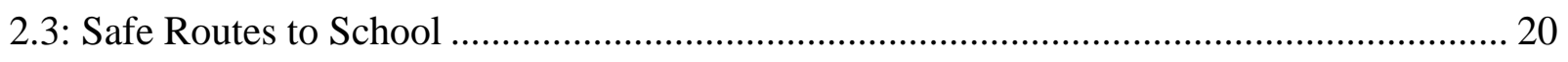

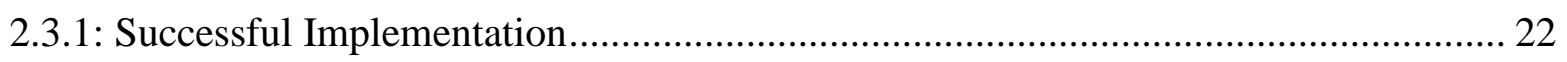

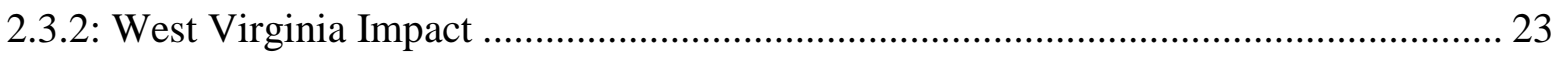

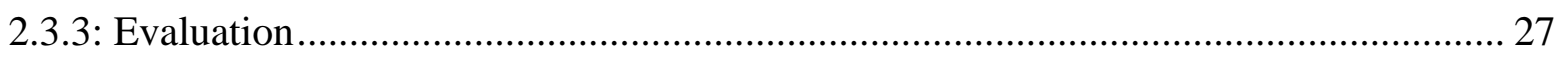

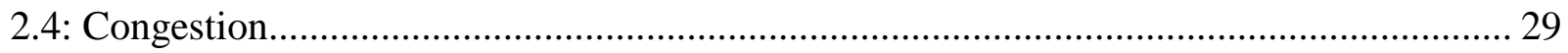

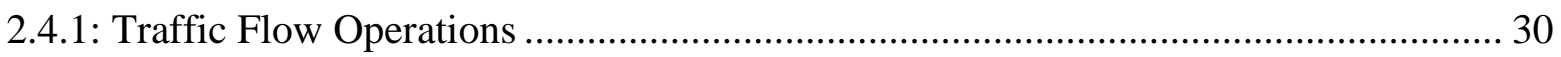

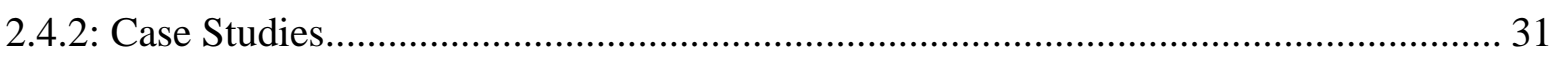

2.5: West Virginia School Zones ………………………................................................. 36

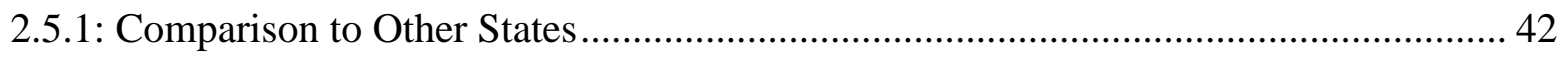

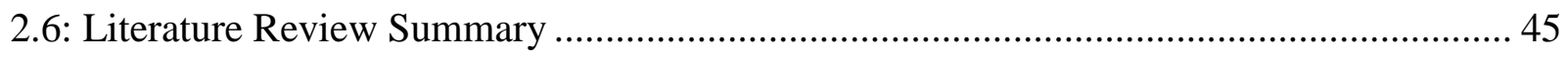

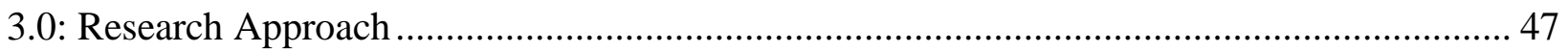

3.1: Survey Development and Distribution......................................................................... 47

3.2: Highway Safety Information System Data ……………………………………….......... 49

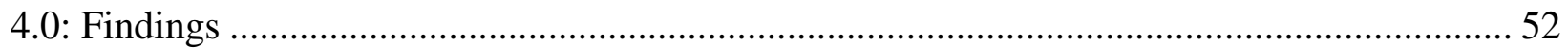

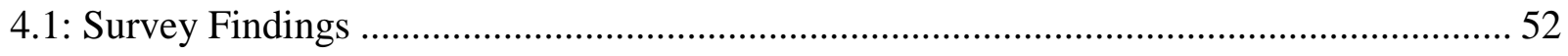

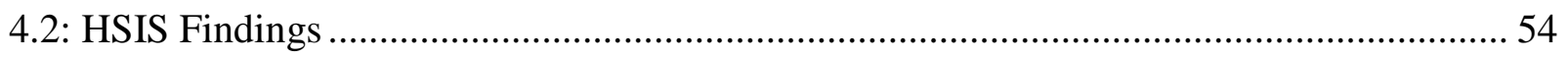

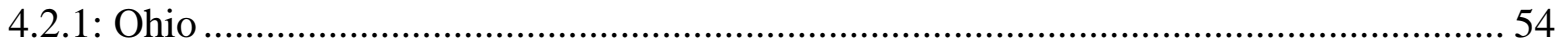

4.2.2: North Carolina ......................................................................................................... 57

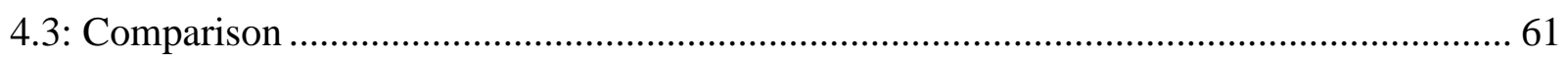

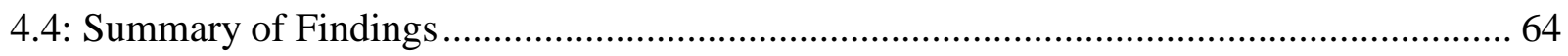

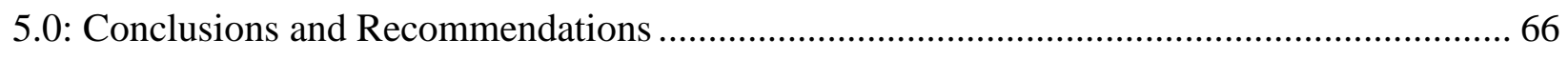

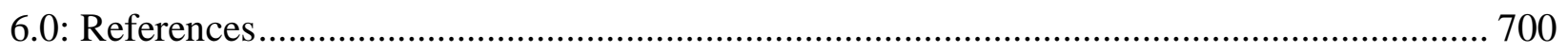




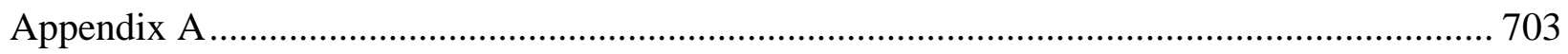

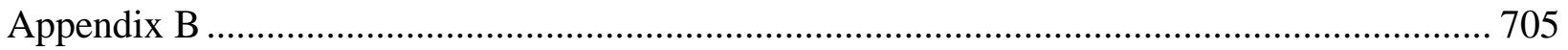

List of Figures

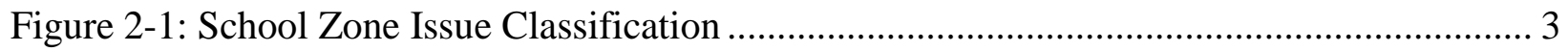

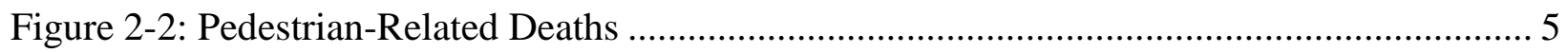

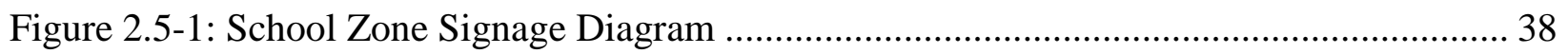

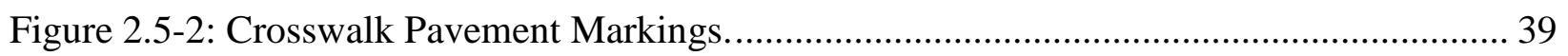

Figure 2.5-3: United States School Zone Speed Limit Distribution............................................ 42

Figure 2.5-4: United States School Zone Speed Limits............................................................. 43

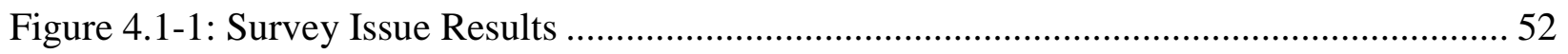

Figure 4.1-2: County and District Mode Choice Comparison ......................................................... 53

List of Tables

Table 2.3-1: West Virginia Safe Routes to School Funding ....................................................... 24

Table 2.3-2: United States SRTS Funding vs. Population Distribution ....................................... 25

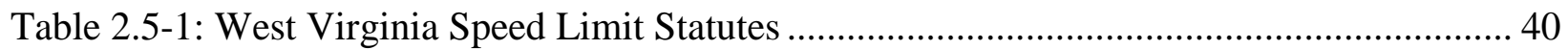

Table 2.5-2: West Virginia Speed Limit Violation Penalties ...................................................... 41

Table 2.5-3: United States School Zone Speed Limit vs. Population............................................. 44

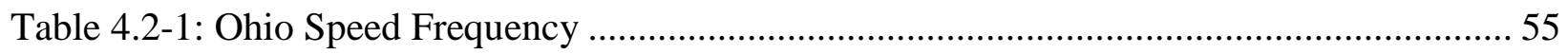

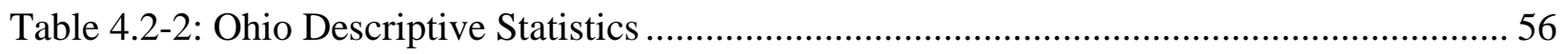

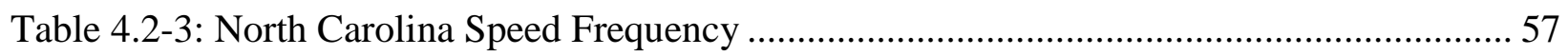

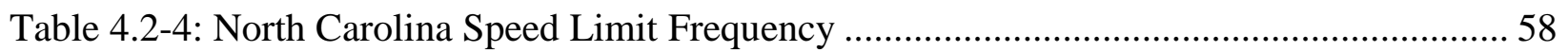

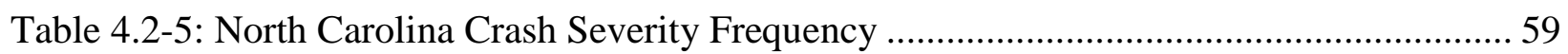

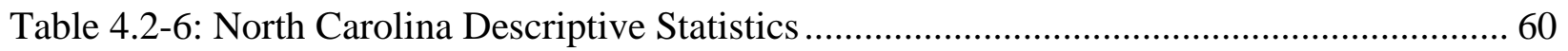

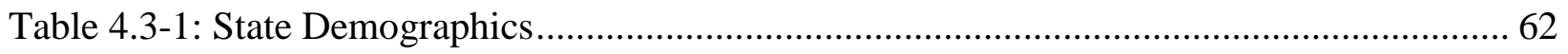

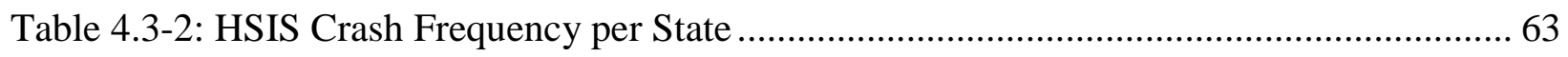


Due to the presence of children and the emphasis placed on their well-being, school zone traffic control strategies typically revolve around safety measures. While this is a worthwhile and necessary endeavor, the solitary focus on safety causes other components of school zone operations to be compromised. This report will conduct an assessment of both the traffic safety and efficiency problems around school zones through a comprehensive review of warrant and laws in West Virginia and other states.

Throughout the research on efficiency and safety issues in school zones, vehicle speed, mode choice and congestion emerged as the main concerns. While these issues are interrelated and are best addressed simultaneously, they are typically treated as separate problems and improvement procedures are targeted at vehicle speed reduction.

Surveys were developed with the purpose of determining the issues most concerning transportation officials throughout West Virginia and the breadth of awareness on the link between safety and efficiency issues. It was found that efficiency and congestion were not emphasized or considered as important as safety issues, and their relationship was not addressed. Furthermore, the lack of communication across disciplines was evident, particularly the lack of awareness from transportation directors and superintendents on the Safe Routes to School programs active within their counties.

Analysis of school zone crash data from the Highway Safety Information System (HSIS) in North Carolina and Ohio investigated the nature of school zone crashes. Through analysis it was determined that majority of crashes are rear-end crashes at low speeds occurring much more frequently when no passengers were present. It is evident that driver behavior changes based on 
the presence of passengers and that drivers are more aware of their actions when children are present. The absence of speed as a contributing factor in most crashes and the lack of pedestrians and bicyclists involved in school zone crashes indicate that safety issues are being misdiagnosed. The best way to reduce school zone crashes and improve traffic flow operations is to target driver behavior and perception through a combination of public awareness campaigns and responsive traffic control devices. By providing drivers with feedback on their performance and educating them on the impact their actions have on the overall safety and efficiency problems in school zones, they are made aware of the problem and more likely to adapt their behavior and comply with proper school zone operations. In order to target congestion, school boards should alter their approach on shifting mode choice. The rural nature of West Virginia school zones does not lend itself to the goals of "walk to school" programs and campaigns should be modified to encompass multimodal options. Designating walkable areas outside of school zones and around bus stops can reduce the number of bus routes and congestion present within the school zone.

When creating school zone traffic flow procedures, alternate programs should be designed for a variety of school zone types; however, uniform application of each scenario should be emphasized in order to decrease driver confusion and increase the likelihood of successful implementation. Likewise, involving a variety of disciplines in the design, implementation, and enforcement phase ensures a higher probability of success. By uniformly addressing safety and efficiency issues in a collective manner, school zone traffic control strategies stand a better chance at long-term success in their implementation. 
School zone traffic patterns and operations have undergone a significant change over the past sixty years. In that time, the predominant mode of student transportation has shifted from walking to riding in a school bus or personal vehicle. This transition is attributed to numerous factors including increased size of schools, school site location and increased accessibility to alternate transportation modes. The consolidation of schools has led to new schools being frequently located at "neutral" sites along high-speed highways, creating an unprecedented situation where the standard $15 \mathrm{mph}$ school zone speed limit may be impractical. Furthermore, the increased presence of personal vehicles in school zones during arrival and dismissal times is causing a major impact on the safety and congestion of school zones. More vehicles lead to more potential pedestrian-vehicle conflicts and a more complicated and inefficient traffic flow pattern. Thus, these conditions continue to worsen as school attendance grows and the current procedures and guidelines in place are inadequately designed for the safe and efficient operation of a modern school zone.

This report explores the current issues in school zones in regards to safety and efficiency. In order to improve the current state of operations and prepare for the development of future issues, a better understanding of the underlying causes must be explored. Throughout the research of school zone issues, some common themes recurred. The main issues associated with school zones are safety operations including vehicle speed and pedestrian operations, efficiency issues including congestion and traffic flow procedures, and issues such as mode choice, vehicle mix and public awareness campaigns relating to both safety and efficiency. From these issues it was determined that school zones should strive to operate in a way that enhances both safety and efficiency since the two are so interrelated. The best way to achieve this standard is through the 
uniform application of procedures and devices and public awareness campaigns that educate all involved parties on the proper conduct within any school zone, no matter the location. Research also indicated that while the standard $15 \mathrm{mph}$ speed limit for all school zones within West Virginia was appropriate at the time it was implemented, it may no longer be practical to have such an obstinate code in place due to the current nature of school zones.

Through interaction with the West Virginia Department of Highways, county Boards of Education and transportation officials and Safe Routes to Schools representatives, a list of concerning issues, which can be classified as either safety or congestion oriented, was generated. This report analyzes the traffic safety and congestion problem in school zones through school zone crash data from other states in order to determine driver and vehicle trends and behaviors within school zones and relate these findings to West Virginia. A survey of district and county transportation officials is also analyzed in order to directly relate these issues to West Virginia. Examination of the current warrants and laws in West Virginia in relation to other states is performed in order to determine the practicality and relevance of these laws within the current state of operations in school zones. The combination of research and statistical data analysis will motivate the recommendations outlined later in the report. 
Throughout the review of literature in regards to school zone issues, there were two recurring themes: safety and efficiency. These issues are often considered separate and unrelated; therefore, solutions to these issues are typically dealt with individually. However, research has shown that the most effective implementation of school zone operation solutions have been when safety and efficiency objectives are combined. This theory is further supported by the breakdown of specific school zone issues. When trying to classify issues as either safety or efficiency concerns, it is difficult to categorize them into one area as there is typically an overlap. The graphic below illustrates this categorization visually, and represents the organization of this report.

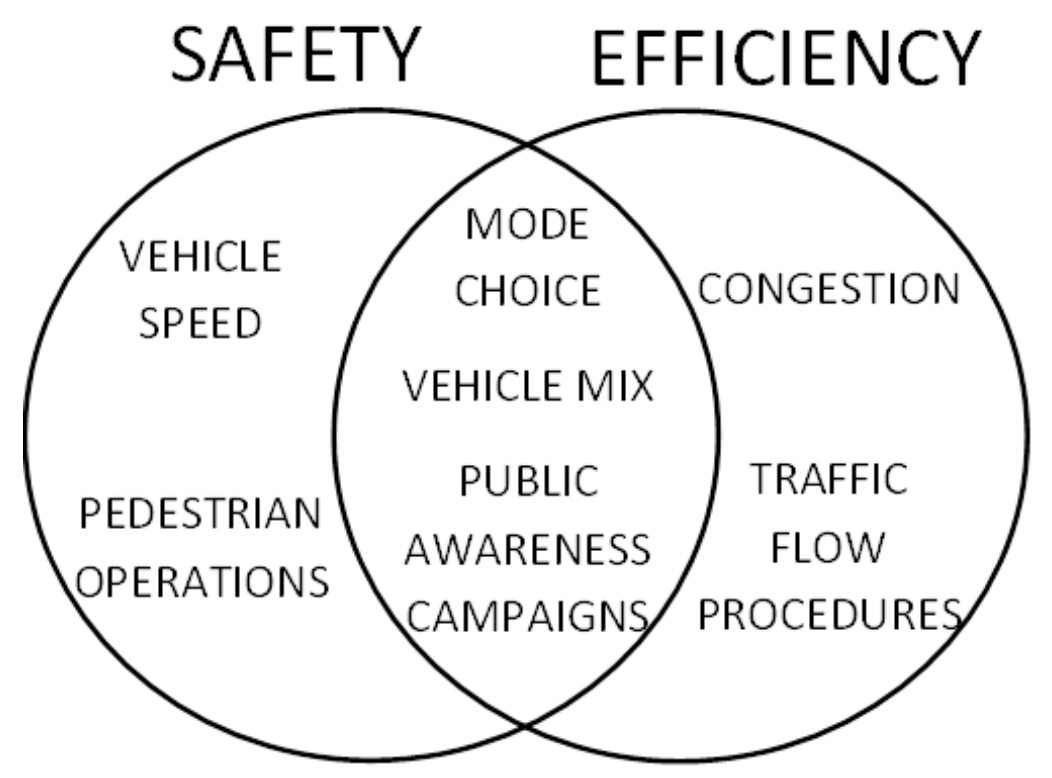

Figure 2-1: School Zone Issue Classification 


\section{Research Methods}

Research on these issues is typically conducted through various study techniques. Detailed discussion of individual studies will identify the study as an observational study, survey distribution, before-and-after field evaluation, speed and volume collection, or program evaluation. Observational studies consist of a written account of the current operations and actions that take place within a school zone. They are non-intrusive and merely provide comments on driver and pedestrian behavior and conclusions consist of recommendations without results to support those claims. They often serve as a precursor to active studies that involve traffic control devices and before-and after field evaluation. Field evaluations consist of data collection (for traffic studies typically volume and/or speed) before and the installation of a traffic control device or procedure and compare the results to determine the impact of the device or procedure.

Safety

When identifying concerns with traffic operations of school zones, safety is typically the most prominent issue due to its direct implications on the well-being of children. While the occurrence of pedestrian fatalities in school zones at the national level is at an all-time low, crash occurrence and fatalities are always cause for concern and attention, especially when children are present. Thus the safety of school zones will always be an essential and relevant transportation concern. 


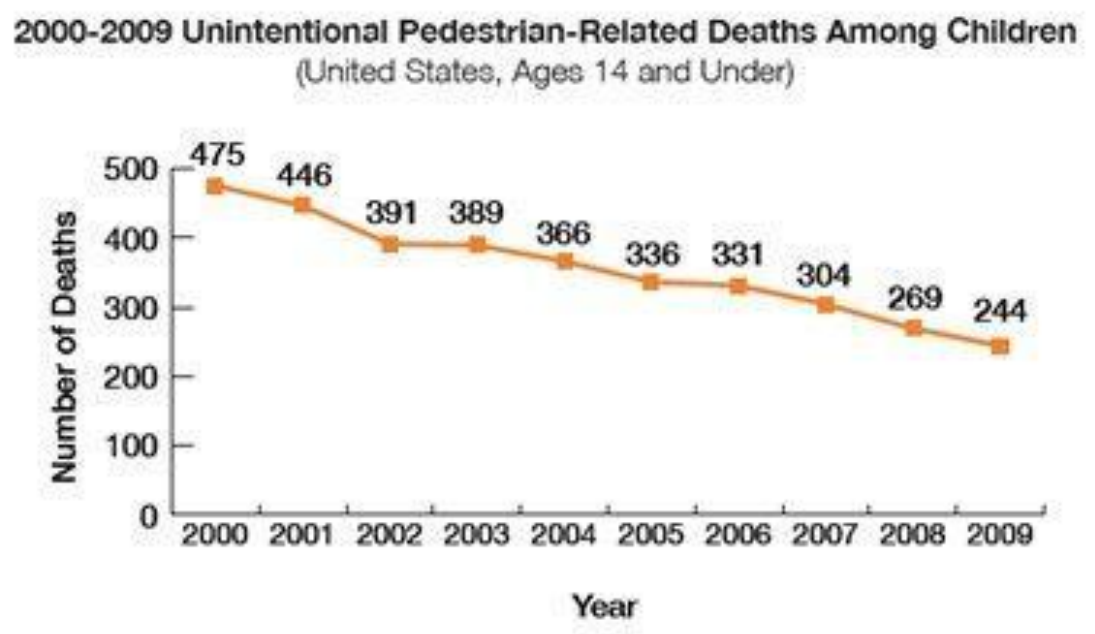

Figure 2-2: Pedestrian-Related Deaths

The safety of school zones varies by site; therefore, many of the traffic studies examined in the research encompassed a variety of school site locations in order to ascertain whether the study represented specific types of school zones or all school zones in general. The various types of traffic studies involved in vehicle speed compliance in school zones include various traffic monitoring devices used to measure vehicle speed, observational studies used to monitor driver and pedestrian behavior, and public surveys used to evaluate public perception and expectation in school zones. In regards to school zone safety, vehicle speed is the most cited problem by parents, teachers, and law enforcement alike. While vehicle speed is not always the most unsafe aspect of a school zone, it is often perceived as such. Thus, the majority of school zone studies are dedicated to vehicle speed reduction.

\section{1: Vehicle Speeds in School Zones}

School zones present a unique roadway zone situation; the school function of a school zone is only applicable during specific hours of the day on specific days of the week during specific months of the year. Observation of vehicles speeding through school zones is only applicable to 
student safety when it occurs during school hours. Many school zones have supplemental signs attached to speed limit signs which indicate when these school zone speeds are in effect. Reduced speed school zones can be confusing to drivers, especially when reduced speeds are provisional. A study in Texas combining law enforcement surveys and speed data collection, found an overall higher compliance with regulatory speeds than school zone speeds, which indicates that drivers base their speed decisions on constants, and obey the speed limit which is more consistently operational (Fitzpatrick 2010). Further complicating matters is the fact that school zone speed limits and operations not only vary by state, but by school. The inconsistency is confusing to drivers, which explains the higher level of compliance with reliable regulatory speeds instead of fluctuating school zone speeds. Thus the need for a uniform set of school zone standards has been a prevalent theme throughout the literature.

Vehicle speed is typically emphasized within the realm of school zone safety due to the impact speed has on crash severity, especially in the instance of a pedestrian-vehicle conflict. One particular study in the Adelaide area of Australia examined the effects of speed reduction on the incidence of fatal pedestrian crashes. Detailed investigations of 176 fatal crashes in $60 \mathrm{~km} / \mathrm{h}$ (37 mph) speed limit zones were conducted and analyzed based the relevance of speed in the cause of death. 133 of these cases were further analyzed through crash reconstruction, impact speed and probability of death comparison, and finally reduced travelling speed scenarios. The relationship between impact speed and probability of death was determined by assigning cases Injury Severity Scores and impact speeds then graphing the results. It was decided that it was not due to random chance that particular accidents were fatal at given impact speeds, and that these fatalities were related to other factors within the accident. In addition, if an accident is survivable at a given speed, it is also survivable at a lower speed. These cases were then reconstructed and 
compared by the same methods at lower impact speeds to determine that relationship. Results indicated that small speed reductions result in a large reduction in impact speed and occurrence of pedestrian collision, sometimes preventing the collision altogether (Anderson 1997).

The relationship between speed and crash severity is particularly important in crashes involving children. A 10 kilometer per hour $(6 \mathrm{mph})$ decrease in speed reduces the probability of a fatality from $85 \%$ to $25 \%$ (Anderson). In order to reduce the occurrence of school zone crashes, in particular, crashes involving fatalities, speed distribution needs to be better understood. Highest vehicle speeds are recorded in rural, undeveloped areas, while lower speeds are most common at suburban school sites. Lower speeds are associated with a large number of access points to the school and the presence of sidewalks and crosswalks. It has also been shown that the longer the speed zone, the greater the increase in driver speed (Fitzpatrick).

\subsection{1: Driver Perception and Behavior}

An extremely important and often neglected part of the vehicle speed issue is the human factor. Drivers who are speeding through school zones estimate their speed much lower than their actual speed. A study conducted in Auckland, New Zealand measured vehicle speed with speed tubes during two 55 minute sessions under three different scenarios. The control scenario was when no children were present, the second scenario was when two children were playing on the sidewalk adjacent to the road, and the third scenario was when the two children were attempting to cross the street. A survey was distributed to drivers at a gas station 500 meters (1,640 feet) from the study site asking them what estimated speed they traveled at in the above situations. Results from these data collections found that during the control condition, drivers traveled very close to their estimated speed (about $56 \mathrm{kph}$ or $35 \mathrm{mph}$ ); however, when the children were present, drivers estimated much lower travel speeds than they were actually going. When the children were 
playing on the sidewalk, drivers estimated a speed of $39.27 \mathrm{kph}(24.4 \mathrm{mph})$ when they were in fact averaging $54.29 \mathrm{kph}(33.7 \mathrm{mph})$, and when the children were attempting to cross the street, drivers estimated speeds of $34.02 \mathrm{kph}(21.1 \mathrm{mph})$ and actually went, on average, $52.78 \mathrm{kph}(32.8$ $\mathrm{mph}$ ). Answers from the questionnaire could be inaccurate due to drivers answering based on what they should be doing rather than what they do in reality; however, whether accurate or inaccurate, these responses indicate that drivers are at least aware that the presence of child pedestrians indicates a reduction in speed. In conclusion, drivers are unaware of how fast they are traveling in the presence of child pedestrians and need some feedback and education on the impact that their speeds have on the safety of these children (Harre 2003).

The gap between driver perception and reality is one that needs to be addressed in order to improve the safety of school zones. This can be accomplished through numerous approaches, the most prominent being driver education and driver feedback. Driver education is commonly achieved through public awareness campaigns designed not only to educate drivers on their responsibilities and expectations in school zones, but also to introduce the public to the issue of school zone safety and why it needs to be addressed. Public awareness campaigns encompass a variety of school zone issues extending outside of safety. Driver feedback is primarily associated with vehicle speed and entails a variety of traffic control devices whose effects have been studied to varying degrees. Many devices have had significant impacts on reducing driver speed, while others have been largely ignored by drivers. Some studies outlining these devices are summarized below and should be further investigated in order to determine their applicability to West Virginia school zones. 


\subsection{2: Speed Reduction Techniques}

All methods aimed at reducing vehicle speed consist of attempts at influencing driver behavior. This can be achieved directly or indirectly in a variety of ways. A speed collection study in Georgia used remote sensing technology, which is similar to the crash-protected Flight Data Recorder, commonly known as the "Black Box." This device collects information about the speed, acceleration and location of the car but has no ways of recording driver reaction or behavior. Over 100 cars in the metro Atlanta area were chosen at random to have the device installed. To choose the school sites for the study, GIS information containing the coordinates of 929 primary schools in the area was analyzed and compared to the trips of the 100 vehicles with the black box. Thirty-three schools contained more than 50 driver trips and were considered for further analysis. These 33 were narrowed down to two based on their current location, whether or not they had a marked school zone and their lack of traffic signals within the school zone. Both sites were elementary schools with sidewalks and signs indicating a school zone but without flashing lights to emphasize the change in speed limit. The data from the drivers' trips within the school zones was analyzed to determine the influence of street geometry, time of day and corresponding traffic conditions, and effect of active school zones on vehicle speeds. Results showed that there was no measured decrease of speeds when in an active school zone, and that the presence of traffic signals and complicated street geometry had the greatest impact on reducing vehicle speed within school zones (Young).

Many studies have shown that school location plays a large part in vehicle speeds throughout the school zone. A study in Calgary, Alberta, Canada examined 20 sites located in residential areas and varied between two-lane and four-lane highways. The study concluded that there was a decrease in speed compliance in zones located along four-lane roads since the wide roadway and 
increased visibility misleads drivers to a sense of security and protection; however, in the presence of a chain-link fence, there was an increase in speed compliance. It is surmised that the presence of the fence provided an obstacle and visual indicator that children were actually present (Tay 2009). Likewise, a speed and volume collection study was analyzed in a report for the Florida Department of Transportation Office of Traffic Operations that recommended a pedestrian lead-phase to give pedestrians a head start when crossing the street and increase their visibility in the roadway. The pedestrian lead-phase introduces an extended all-red interval at the intersection, stopping all vehicular traffic for an allotted interval, allowing pedestrians adequate crossing time. The combination of school site location and visual reminders of child presence are non-invasive solutions to reducing vehicle speed. School site location requires awareness and forethought in the design and planning mode, indicating the need for a set of standards outlining safe practices for school zone development. Visual cues to remind drivers of child presence consist of fences and various signs and can be implemented in pre or post construction of a school zone. Due to their relatively simple installation, these visual cues should be utilized more frequently.

Slower approach zones have also been shown to have an impact on vehicle speed. Approach zones are the speed zones encountered by drivers immediately before entering a school zone. Utilizing signage as a visual reminder to drivers of the reduced speed zone and the presence of children causes them to slow down. A study of 40 elementary schools in small to mid-size cities in Washington State investigated the impact of various signs on vehicle speeds in school zones. The schools were divided into four categories based upon their approach speeds and the type of signage they had at the onset of the school zone. Results indicated an overall slower average speed at sites with slower approach speeds and vice versa (Saibel 1999). By the same token, 
many schools located near high-speed highways use buffer zones to transition drivers into the severe speed reduction in school zones. For example, if the regulatory speed on a road was 70 $\mathrm{mph}$, the buffer zone would be $55 \mathrm{mph}$, which would finally lead into the school zone with a posted speed of $35 \mathrm{mph}$. These transitions provide drivers with visual cues to remind them of their expectation within the school zone and results in higher compliance and reduced speed.

Another way to influence driver behavior is through interactive traffic signs or devices. There are a variety of traffic control devices utilized in school zones that range from pavement markings to flashing beacons to speed displays. Some studies use a control situation to evaluate the impact of multiple devices, while others use a variety of situations to determine the impact of a singular device. A study conducted by the National Highway Traffic Safety Administration (NHTSA) in Portland, Oregon aimed to determine how automated speed enforcements (ASE) impacted speed reduction efforts in school zones and how the public accepted and perceived their presence. ASE measures speeds of vehicles while capturing images of the speeding vehicles, resulting in automatic ticketing of violators. ASE's are highly visible and cause minimal disruption of traffic flow, making them highly suitable for school zones. School speed limits in Oregon are $20 \mathrm{mph}$ 24 hours a day. This study used ASE's in five different school zones 2-3 times a week for a 3 month period during the school year. Results were compared to five other school zones in the surrounding area where no ASE were present. All sites had flashing beacons attached to school speed limit signs that could be turned on or off. A publicity campaign and road signs were initiated in order to inform drivers of the presence of ASE. The study found that average speed dropped when ASE's were present when flashing beacons were on or off; however, the drop in speed was 3-4 mph more when flashing beacons were on. Furthermore, speed reduction lasted up to at least a month after ASE was discontinued. Comparison sites showed limited change in 
speed; however, as seen in the test sites, speeds were lower when the flashing beacon was on. Thus, it can be concluded that ASE create a lower speed environment, especially when paired with flashing beacons.

Similarly, the previously mentioned Washington state study by Saibel and colleagues investigated the impact of various signs on vehicle speeds in school zones. The four types of signs were signs that indicated that school speed limits were in effect when specific times were listed (signs with no indication were included in this group), when yellow beacons were flashing, "when children are present," and when orange flags were present. Results indicated that type of sign had no effect on speed in slow-approach zones; however, flashing beacon signs showed the only measured speed decrease in fast-approach zones. The decrease was slight $(5-7 \mathrm{mph})$; however, $5 \mathrm{mph}$ could be the difference between a pedestrian-vehicle crash resulting in minor injuries or fatalities. It was concluded that when schools are located in high-approach zones, flashing beacon signs are effective in slowing down vehicles. A before-and-after study in North Carolina also examined the effects of adding flashing beacons to speed limit signs on school speed limit compliance. The study took place at 30 sites in North Carolina. Fifteen of the sites had had flashing beacons installed for at least three years and the other 15 had none. The sites ranged in geographic location, geometric features, and posted school zone speed limits. Results of the study showed that sites with flashing beacons had slightly better speed compliance rates than those without. Across all sites a noticeable decrease in average speed was noted during school hours rather than non-school hours; however, these speeds were still higher than posted limits. Sites with higher posted speed limits showed significantly higher compliance rates in flasher sites than in non-flasher sites. The recommendations of this study were to encourage other methods of speed limit compliance in addition to flashing beacons and that the greatest 
effect on speeding in school zones is made when the public gets involved, demands enforcement, and is made aware of the issue (Simpson 2008).

Flashing beacons are commonly used as a supplement to the "Begin School Zone" sign and are required in some states; however, the practice of rear-facing beacons is not typically used. Rear facing beacons are simply flashing beacons located at either end of a school zone facing the zone, to serve as a reminder and indicator of the location of the end of the zone. The focus of an experiment in College Station, Texas was to determine if rear-facing school speed limit beacons would reduce speeding in long school zones or zones containing intersections where drivers might forget that they are in a restricted speed area. This before-and-after study was conducted at four separate sites located near College Station, Texas. The results of this study found speed reductions in three of the sites. The only site that experienced no change in speed compliance was the zone with no intersections and of a normal length. As a result, it can be concluded that the installation of rear-facing school speed limit beacons creates a reduction in speeding in school zones of a substantial length. This study resulted in a revision of the Texas MUTCD (Hawkins 2007).

Another type of traffic control device that provides actual feedback to drivers on their actions within school zones is a speed reduction display. A speed reduction display is a type of Speed Monitoring Device (SMD) which is essentially a digital sign that uses radar to show the driver both the speed limit and the speed at which they are currently traveling in hopes that the comparison will urge drivers to comply with posted speed limits. A case study conducted in South Korea was set up to determine whether or not speed reduction displays were effective devices in decreasing average driver speed in school zones. The site of the study was selected based on its presence along a roadway with high visibility, low congestion, and no presence of 
other signals in order to measure the sole impact of the SMD. Both a short-term and long-term study was conducted so that future impact could be measured. The short term study found a noticeable reduction in speeding upon initial installation of the SMD. The speed slowed at the location of the SMD, increased slightly through the school zone, but remained lower than the average speeds before SMD installation. While speeds increased at night, the overall speed distribution throughout the school zone mimicked the daytime distribution. The long-term study showed an increase in average speed, but it was still lower than initial conditions. It was also noted that SMD presence not only decreased speeding, but also changed driver behavior, which led to an overall increase in safety throughout the school zone (Lee 2006).

Another field evaluation study utilizing SMDs conducted in Utah in 2005 found that efficiency and safety vary by site and that SMDs reduce excessive speeding and have no recorded negative impacts on the safety of a site. In addition to the SMD study, a literature review and public opinion survey was also conducted, and comprehensive conclusions established that improving speed limit compliance in reduced speed school zones is best achieved through the incorporation and integration of education, traffic engineering, and law enforcement (Saito 2005).

Regardless of the type of traffic control device, it has been shown that drivers are more compliant with posted speed limits when they are given reminders or feedback on their performance. A reduced speed school zone is an interruption in traffic patterns that can easily be forgotten by a distracted driver. By implementing standards that require supplemental driver feedback, vehicle speeds through school zones could be considerably reduced.

\section{2: Mode Choice}

While traffic control devices provide the illusion of a "quick fix," their impacts are often minimal, expensive, and primarily impact the safety of a school zone and often ignore efficiency. 
Other alternative solutions to school zone safety can be applied cheaper and more easily. For example, encouraging students to shift their mode choice from personal vehicle to walking or riding the school bus reduces congestion by reducing the amount of vehicles in a school zone during arrival and dismissal times while simultaneously improving safety by eliminating potential pedestrian-vehicle conflicts. The inclusion of mode choice in both the safety and efficiency components of a school zone make it a prime solution for school zone improvement alternatives.

The primary modes used by students to travel to and from school are school bus, personal vehicle, and walking or biking. Results indicated that over half of children arrived to school by car. Among walkers, a higher percentage were male than female, although the older students were more likely to walk than younger students, regardless of gender (Kweon 2006). In urban settings, some students utilize public transportation; however, due to the rural nature of West Virginia as a whole, it is nonexistent in West Virginia school zones. Student transport by personal vehicle is divided into two types: personal vehicle with parent driver and student as a passenger and personal vehicle where student is the driver. In the case of older siblings dropping younger siblings off at school en route to their school, the driver and the passenger could potentially be students. Women are less likely than men to choose non-motorized transportation due to their increased responsibilities and obligations to the household. In addition, the higher number of available vehicles, the higher likelihood one has of using motorized transportation (Rodriguez, 2004). Throughout West Virginia, school bus ridership is the most common mode choice for students. This is most likely attributed to the low population of the state and the large land area serviced by a single school. The youngest students are more likely to be driven to 
school by a parent, while many older students are given more independence and either drive themselves to school or ride the bus (Beck 2008).

\subsection{1: Barriers Preventing Children from Walking to School}

Over the past 60 years, school zones across the country have experienced a mode shift from majority of students walking to school toward an increasingly large number of students traveling in a personal vehicle. This shift is due to a variety of reasons, such as the increased accessibility of personal vehicles. The number of vehicles per household is typically proportional to the number of drivers per household, whereas in the past there was only one vehicle per household, and students had no choice but to walk or ride the bus to school. The patterns and influences of children's travel was further researched in a 2005 dissertation utilizing data from the National Household Travel Survey, the census, and FBI uniform crime reports. It was found that children travel predominately by car at an average of 31 miles a day, most likely to school. Travel time has the highest impact on the chosen mode of transportation, and gender and race have little impact on the decision to walk (McDonald 2005). While this is true, there are some tendencies among parents to treat females and young students more protectively than their counterparts. For example, in order to encourage more students to walk to school, the current practice in Texas is that buses are only provided to children who live outside of a two mile radius of the school or must cross a major arterial to get to school. A survey of students within walk zones of four different schools found that over half of these students arrived to school by car. Among walkers, there was a higher percentage of males rather than females, although older students were more likely to walk than younger students, regardless of gender. The average walking distance was 0.71 miles, and the average biking distance was 0.93 miles, both of which fall well below the designated two-mile walk zone established by the state (Kweon 2006). As areas have expanded 
and populations have grown, many schools have consolidated, causing the number of students within walking distance to school to decline rapidly, and as shown by the Texas study, a standard two-mile walk zone is an impractical distance, especially among young children and should be evaluated and reassigned dependent upon each school's characteristics.

A nationwide survey conducted by the Centers for Disease Control and Prevention in 1999 found that safety along walking routes is often measured by perceived rather than real danger. In this particular study, safety was indicated as pedestrian-vehicle conflicts. Results indicated that a child is more likely to walk to school when no barriers are present; however, most surveys indicated the presence of at least one barrier. The Centers for Disease Control and Prevention concluded that public health and community programs should work harder to create programs that increase the accessibility of walking and biking modes for children by improving the safety of the routes, thereby encouraging more children to walk or bike to school. Another nationwide study conducted almost a decade later reported the same barriers preventing children from walking to school; the most common barrier preventing walking was distance, followed by the perception of traffic danger by parents; however, overall, a very small percentage of children could even potentially walk to school because few live within walking distance. Based on these findings, it was concluded that programs aimed at increasing walking and biking to school should focus on the students that are located within walking distance by making safety improvements, such as reducing speed and other engineering countermeasures (Beck 2008).

Parents' decisions are clearly impacted by the age and gender of their children and play a role in their perception of safety for their children. Among parents, the most commonly mentioned barriers preventing children from walking or biking to school were distance and safety along the route; however, safety is a relative measurement, and its value varies from parent to parent. The 
focus of programs aiming to increase the number of students walking to school should reevaluate their goals and focus on easing the fears of perceived and nonexistent danger by parents and targeting only students within a reasonable walking distance. By addressing parents main concerns with walking, advocates of this mode choice are much more likely to convert more students into walkers.

Another barrier preventing children from walking to school, particularly applicable in West Virginia, is weather. West Virginia and other states that experience all four seasons face winter weather conditions that are unsuitable for children to be walking in. Severe weather coupled with mountainous terrain and large school districts makes the challenge of increasing walking as a viable mode of transport for students in West Virginia a substantial challenge. Fortunately, there are other factors that influence students' mode choice and many simple, cost-effective adjustments that can be made to a school zone site that impact mode choice. These factors and adjustments are discussed in greater detail in the following sections of the report.

\subsection{2: Environmental Influences}

In addition to distance and safety, environmental surroundings largely impact the mode by which students travel to school. Students who walk or bike to school tend to live in older neighborhoods with increased amounts of greenery and high housing density, while bikers tend to live in newer neighborhoods with more sidewalks (Kweon 2006). These features heavily influence the perceived safety of a route by parents, which is likely why students along these types of routes are more likely to walk or bike to school. A study in North Carolina aimed to determine the impact of physical environment on a travelers' mode choice. The data model compared environmental variables such as walk/bike path presence, topography, street network, sidewalk availability, and population density, with survey responses indicating preferred travel 
mode choice in the local area. Results indicated that increased mixed land use corresponded to an increase in walking or biking, which indicates that parents and students value the travel time savings gained from walking or biking more than time savings experienced from motorized trips. Local topography is also a major factor in mode choice in that the steeper the slope, the less likely a traveler will choose to walk or bike. The strongest correlation was between the number of sidewalks and the increased likelihood of walking to a destination. Thus, it was concluded that the presence of mixed land use and connective street and sidewalk networks has the greatest impact on encouraging non-motorized transportation modes in urban environments (Rodriguez, 2004).

Environmental factors, such as street patterns, housing density and land use have a major impact on a child's motivation to walk or bike to school (Kweon 2006). School walking paths located in residential neighborhoods are going to appear much more appealing from a safety aspect than walking paths along freeways, regardless of distance. Relocating schools into neighborhoods address both distance and safety, although this will only provide positive results in high density areas and elementary schools. Schools and land use planners need to cooperate with one another to change community designs and encourage walking to school by incorporating current policies with existing site characteristics (McDonald 2005). For example, acreage required for school siting should be reduced whenever possible, and when planning school sites, incorporate mixed land use into the design. Both of these actions would increase the number of students within walking distance and their likelihood of utilizing that transportation option. By taking mode choice and subsequent issues into consideration during the planning process, many school zone mode-related concerns could be prevented altogether (Beck 2008). In conclusion, schools and land use planners need to cooperate with one another to change community designs and 
encourage walking to school by incorporating current policies with existing site characteristics (McDonald 2005).

A 1977 report for the Federal Highway Administration investigated the impacts of schools on highways and vice versa when they are located adjacent to one another. The report included recommendations for improving their co-habitation. Since the findings of this report are dated, it provides a good reference point for what has been accomplished and neglected in the enhancement of school safety near highways. In regards to safety, it was recommended that specific individuals within the school system and the highway maintenance staff be assigned the responsibility of organizing safety procedures and maintain continued cooperation and communication between themselves In addition, these individuals should consider hazards along a route rather than distance of the route for walkers (Wells 1977). These same recommendations hold true today, and unfortunately, have not been implemented frequently enough to deter the same issues from occurring over and over again.

Changing a parent's mind about what distance is too far for their child to walk is a near impossible task; however, easing parents' fears about the safety of a route is a manageable goal. Programs combining awareness and education about the actual dangers and benefits that arise from walking to school is the most cost-effective and immediate way to shift a child's mode choice from riding in a vehicle to walking to school. Many programs of this nature currently exist and are operational throughout the United States and West Virginia, the most well-known being the Safe Routes to School initiative.

\section{3: Safe Routes to School}

Safe Routes to School is a national program that was developed to address the objectives of the Safe, Accountable, Flexible, Efficient Transportation Equity Act: A Legacy for Users 
(SAFETEA-LU). In 2005, congress approved \$612 million in funding for the SAFETEA-LU to distribute to all 50 states and Washing D.C. as it saw fit. All states are eligible for SAFETEA-LU funding after an application, proposal and award process (Crowe 2009). The Safe Routes to School program has two primary goals: encourage students to walk or bike to school and to improve the safety of walking and biking routes. Secondary goals entail reducing environmental impacts, such as reducing traffic, fuel consumption and air pollution near schools (Winters 2011).

The program's intent is to encourage students to walk to school while addressing health, fitness, traffic relief, environmental awareness and safety goals. Safe Routes to School tries to solve safety issues by four different methods: education, encouragement, enforcement and engineering. Funding is allotted to two different types of projects: infrastructure projects, which consist of engineering improvements, and non-infrastructure projects, which include education, enforcement and encouragement programs. Engineering methods are involved in both infrastructure and non-infrastructure projects and can be implanted at a low or high cost depending on the extent of the project. Some low-cost solutions to these problems include walkway repair and maintenance, removing obstacles, high visibility crosswalks, proper area signing, school walking/bicycle route maps, modified drop-off/pick-up operations, and holding traffic safety days. Some high-cost engineering solutions include separation of pedestrian and vehicle facilities, bicycle lanes, crossing enhancements, and traffic calming measures similar to those mentioned in section 1.2.1. The main problems to be addressed by the engineering methods are improving walkways, providing better connections between walkways and reducing vehicle travel speed (Parisi 2005). 
Non-engineering methods are more commonly employed due to their significantly lower price of implementation. They are typically non-infrastructure projects that utilize public awareness campaigns to advertise their message and goals through the other methods of Safe Routes to School application. Encouragement is used to create incentives. Regardless of the reason a student is not using alternative modes of transportation; they are unlikely to change the status quo without an incentive in place. Awarding students who walk or bike to school with early dismissal or other privileges encourages other students to see the benefits of this choice; furthermore, education is used to help students and parents understand why walking is beneficial. Recognizing the health benefits of daily physical activity and how this generates healthy lifestyle choices can make the decision to use an active form of transportation much more important. Enforcement is used to make walking a safer mode choice. Whether the issue is fear of abduction, crossing heavily trafficked roads, or a child getting lost, Safe Routes to School can provide a law enforcement officer or other authority figure to safely guide children along a designated walking route. Each site and situation is unique and has its own characteristics that should be dealt with on a case-by-case basis.

\subsection{1: Successful Implementation}

The steps in creating a successful Safe Routes to School program are as follows: form a multidisciplinary task force, hold public meetings to address unique issues at school, conduct a field audit on site, identify specific problems to address, and develop a plan to solve these problems. The task force should be comprised of a diverse group of community members with different concerns, interests, and information that can be used to address all possible issues and bring differing viewpoints to the table. The collection of information may be the most important step in the process as it provides the groundwork for the objectives and design of the project. The 
program has been the most successful in areas that are dedicated to the program's goals. When community members and officials are promoting Safe Routes to School, more progress is made. Students must learn to value their health and the environment, and Safe Routes to School must continue to strive to help increase the safety of the students. By creating a safer commute to school, students can grow to become more active and more environmentally conscious. For the Safe Routes to School program to stay active, schools must be willing to accept its advice and take the necessary measures to protect their students.

The most successful implementations of the Safe Routes to School program have been in areas where the community was aware, involved and supportive of the initiative. School age pedestrians are the main benefactors and targets of this program, but they follow the excitement and example of the adults involved. Many states have used the funding to create walking paths providing access not only to schools, but also to community attractions, such as parks, neighborhoods and colleges located within the town, thereby benefiting school-age students and community members. These walking path extensions have also introduced the idea of "walking school buses," where groups of students who live near each other are accompanied to and from school by an adult chaperone. The most successful cases of student participation have been in schools where students were provided with an incentive. The Safe Routes to School program is best implemented when states use funding to first create proper infrastructure to increase accessibility of walking/biking routes for students and then create a community awareness campaign to encourage the use of these facilities (Crowe 2009).

\subsection{2: West Virginia Impact}

As of 2009, every state has its own operating Safe Routes to School program. These programs must identify problem areas in their respective states, and propose solutions or funding scenarios 
to the national Safe Routes to School programs (Crowe 2009). Currently in West Virginia there are 58 infrastructure and non-infrastructure projects affecting 71 schools in 22 counties. The following table provides a breakdown of the funding allotted to West Virginia from 2005 to 2012 for Safe Routes to School projects.

Table 2.3-1: West Virginia Safe Routes to School Funding

\begin{tabular}{|c|c|c|c|}
\hline Year & Funding & $\begin{array}{c}\text { Award } \\
\text { Amount }\end{array}$ & Projects \\
\hline 2005 & $\$ 1,000,000$ & ----- & ----- \\
\hline 2006 & $\$ 990,000$ & ----- & ---- \\
\hline 2007 & $\$ 1,000,000$ & $\$ 872,226$ & 11 \\
\hline 2008 & $\$ 1,000,000$ & $\$ 1,699,874$ & 17 \\
\hline 2009 & $\$ 1,000,000$ & $\$ 1,609,817$ & 15 \\
\hline 2010 & $\$ 1,000,000$ & $\$ 816,100$ & 7 \\
\hline 2011 & $\$ 1,000,000$ & $\$ 971,000$ & 8 \\
\hline 2012 & $\$ 933,567$ & ----- & ---- \\
\hline Total & $\$ \mathbf{8 , 0 9 0 , 6 9 7}$ & $\mathbf{\$ 5 , 9 6 9 , 0 1 7}$ & $\mathbf{5 8}$ \\
\hline
\end{tabular}

While Safe Routes to School awarded funding to West Virginia starting in 2005, the actual construction of projects did not begin until 2007. This was due in large part to the implementation of an eight-step annual cyclic grant process. These steps include: marketing the program, conducting WV-SRTS workshops and school visits, submitting intent to apply forms, submitting applications, reviewing the applications, recommending applicants to the commissioner and governor, announcing the WV-SRTS grant recipients and updating and improving the application manual and evaluation criteria. The last step has been crucial in the process due to its use of customer-driven feedback. This grant process led to the awarding of more than $\$ 774,000$ in infrastructure funds and over $\$ 97,000$ in non-infrastructure funds in 2007. In addition to the implementation of the grant process, a Resource Packet was also created to 
educate potential grant applicants on the program. West Virginia Safe Routes to School has marketed the program through various sources including mailings, web materials, promotional items and information and education briefings. They have also utilized mass media through publications in newsletters, press releases and television spots on local channels (saferoutesinfo.org 2013). However, despite these efforts, West Virginia still struggles nationally to compete with other states for funding proportional to its population rank. The following table shows all 50 states and the District of Columbia and their funding allotment since the creation of the Safe Routes to School program in 2005.

Table 2.3-2: United States SRTS Funding vs. Population Distribution

\begin{tabular}{|c|l|c|c|}
\hline $\begin{array}{c}\text { Safe Routes } \\
\text { to School } \\
\text { Funding Rank }\end{array}$ & State & $\begin{array}{c}\text { Total Funding } \\
(\mathbf{2 0 0 5} \text { - 2012) }\end{array}$ & $\begin{array}{c}\text { Population } \\
\text { Rank }\end{array}$ \\
\hline 1 & California & $\$ 137,155,013$ & 1 \\
\hline 2 & Texas & $\$ 90,066,831$ & 2 \\
\hline 3 & New York & $\$ 63,045,487$ & 3 \\
\hline 4 & Florida & $\$ 58,239,336$ & 4 \\
\hline 5 & Illinois & $\$ 47,009,829$ & 5 \\
\hline 6 & Pennsylvania & $\$ 41,254,172$ & 6 \\
\hline 7 & Ohio & $\$ 40,421,863$ & 7 \\
\hline 8 & Michigan & $\$ 36,916,932$ & 9 \\
\hline 9 & Georgia & $\$ 34,111,703$ & 8 \\
\hline 10 & New Jersey & $\$ 31,294,169$ & 11 \\
\hline 11 & North Carolina & $\$ 30,692,590$ & 10 \\
\hline 12 & Virginia & $\$ 26,451,718$ & 12 \\
\hline 13 & Indiana & $\$ 23,399,380$ & 16 \\
\hline 14 & Washington & $\$ 22,469,209$ & 13 \\
\hline 15 & Arizona & $\$ 22,013,589$ & 15 \\
\hline 16 & Massachusetts & $\$ 21,760,232$ & 14 \\
\hline 17 & Tennessee & $\$ 21,254,181$ & 17 \\
\hline 18 & Missouri & $\$ 20,998,212$ & 18 \\
\hline 19 & Maryland & $\$ 19,911,337$ & 19 \\
\hline 20 & Wisconsin & $\$ 19,526,738$ & 20 \\
\hline 21 & Minnesota & $\$ 18,573,023$ & 21 \\
\hline & & & \\
\hline
\end{tabular}




\begin{tabular}{|c|c|c|c|}
\hline 22 & Alabama & $\$ 17,309,568$ & 23 \\
\hline 23 & Louisiana & $\$ 16,997,800$ & 25 \\
\hline 24 & Colorado & $\$ 16,878,549$ & 22 \\
\hline 25 & South Carolina & $\$ 15,506,430$ & 24 \\
\hline 26 & Kentucky & $\$ 15,066,292$ & 26 \\
\hline 27 & Oklahoma & $\$ 13,680,141$ & 28 \\
\hline 28 & Connecticut & $\$ 13,122,583$ & 29 \\
\hline 29 & Oregon & $\$ 13,017,098$ & 27 \\
\hline 30 & Mississippi & $\$ 12,233,113$ & 31 \\
\hline 31 & Utah & $\$ 11,500,040$ & 34 \\
\hline 32 & lowa & $\$ 11,419,586$ & 30 \\
\hline 33 & Kansas & $\$ 11,031,299$ & 33 \\
\hline 34 & Arkansas & $\$ 10,985,371$ & 32 \\
\hline 35 & Nevada & $\$ 10,383,571$ & 35 \\
\hline 36 & New Mexico & $\$ 8,520,815$ & 36 \\
\hline 37 & Alaska & $\$ 8,478,237$ & 47 \\
\hline 38 & Vermont & $\$ 8,360,909$ & 50 \\
\hline 39 & Rhode Island & $\$ 8,196,837$ & 43 \\
\hline 40 & Maine & $\$ 8,186,623$ & 41 \\
\hline 41 & Nebraska & $\$ 8,157,362$ & 37 \\
\hline 42 & Montana & $\$ 8,156,235$ & 44 \\
\hline 43 & Delaware & $\$ 8,145,330$ & 45 \\
\hline 44 & Dist. of Col. & $\$ 8,140,507$ & 49 \\
\hline 45 & South Dakota & $\$ 8,135,194$ & 46 \\
\hline 46 & Hawaii & $\$ 8,122,668$ & 40 \\
\hline 47 & West Virginia & $\$ 8,090,697$ & 38 \\
\hline 48 & North Dakota & $\$ 8,074,751$ & 48 \\
\hline 49 & Idaho & $\$ 8,033,682$ & 39 \\
\hline 50 & Wyoming & $\$ 8,007,555$ & 51 \\
\hline 51 & $\begin{array}{l}\text { New } \\
\text { Hampshire }\end{array}$ & $\$ 8,007,473$ & 42 \\
\hline
\end{tabular}

Overall, Safe Routes to Schools funding is primarily proportional to state population rank throughout the United States. The funding for most states matches their population rank exactly, with an overwhelming majority within one or two spots. A positive discrepancy indicates a funding rank higher than population rank; consequently, a negative discrepancy indicates a funding rank lower than population rank. The largest positive discrepancy is in Vermont, which 
ranks $50^{\text {th }}$ in overall population and $38^{\text {th }}$ in Safe Routes to School funding. Idaho, on the other hand, has the largest negative discrepancy ranking $39^{\text {th }}$ in overall population and $49^{\text {th }}$ in Safe Routes to School funding. West Virginia ties with New Hampshire for second highest negative discrepancy behind Idaho. West Virginia ranks $38^{\text {th }}$ in the United States for state population and $47^{\text {th }}$ in total Safe Routes to School funding. While most states are competitive in garnering funding relative to their overall population, West Virginia funding is lacking in comparison. This is likely due to lack of campaigning for funds and lack of advocates for the Safe Routes to School program within the state. New legislation is currently being generated and can hopefully aid states like West Virginia in accruing more funding. For example, in July 2012, Congress passed a new transportation bill; Moving Ahead for Progress in the $21^{\text {st }}$ Century (MAP-21). Beginning in October 2012, Safe Routes to School activities became eligible to compete for funding alongside other programs, including the Transportation Enhancements program and Recreational Trails program, as part of a new program called Transportation Alternatives (saferoutesinfo.org 2013).

\subsection{3: Evaluation}

Since Safe Routes to Schools programs are relatively new in the United States, there have been few evaluations on the effectiveness of the program initiatives thus far. Many strategies being implemented now are based on assumptions. Safety, not distance, is assumed to be the main reason that parents drive their children to school; however, when surveyed, parents listed convenience as the number one reason they drove their children to school. If that is the case, targeting safety improvements and infrastructure projects is not going to improve walking rates among students. Another issue is that a small percentage of a school's student body lives within walking distance of the school, which is the target population of the Safe Routes to School 
program; therefore, the majority of the students cannot reap the benefits of the Safe Routes to School facilities. School boards currently rely solely on school buses for public pupil transport. If schools are interested in decreasing vehicular traffic, they should implement use of multimodal transportation, by way of Safe Routes to School programs and introduce "walking buses," which would be operated by the school. Perhaps the most difficult problem facing Safe Routes to School program implementation is that the goals of the program contradict one another. By addressing the improved safety of walking routes to schools, Safe Routes to School programs would target schools where there were already a large, established number of walkers, which would do little to add more walkers and increase incentive to walk. On the other hand, if the Safe Routes to School program targets schools with no infrastructure to support walking to school, odds are that it is located in an area where there are a small percentage of students who would be impacted by additional infrastructure (McDonald 2009).

In addition, although Safe Routes to School programs address safety issues in a variety of ways, the engineering perspective of Safe Routes to School planning is often neglected or incorporated as a last-minute addition to projects. The transportation engineering perspective is the fundamental and perhaps most effective resource available to Safe Routes to School programs and should be utilized throughout the entire process (Parisi 2005). Gaining an engineering insight early in the design process could eliminate potential transportation issues at a school while simultaneously saving money on the project. In conclusion, there has been considerable funding provided to programs designed to improve schools' walkability; however, this does little to address the more commonly listed reason that children do not walk to school: distance. In order to determine the validity of these "walk to school" programs, the importance of this objective must be established (McDonald 2005). 


\section{4: Congestion}

Most programs associated with shifting student mode choice focus on safety as the main goal or area of concern; however, the issue of congestion is often a more pressing matter that can indirectly enhance safety. Throughout all realms of transportation, significant changes have taken place over the past six decades. In that time, the predominant mode of transportation has shifted significantly toward private vehicle. In the past, many people would walk or use public transportation due to lack of personal vehicles or proximity to destinations. Most households owned one vehicle at most and other modes of transportation were necessities; however, in today's society, the number of vehicles per household is often proportional to the number of drivers in the household. This transition is attributed to numerous factors including an increase in average household income, increased number of workers per household, and urban sprawl, which limits access to alternate transportation modes. This drastic increase in the number of vehicles on the road has led to roadway congestion becoming one of the most pressing issues in transportation today. This congestion has trickled down to all aspects of transportation including school zones, compromising the efficiency of operations in the process. In order to maximize the efficiency of a school zone, congestion must be alleviated.

Congestion is the result of road users' lack of awareness on their contribution to the issue. Drivers only consider the personal effects of choosing to drive their vehicle on a busy route, not the impact that their presence imposes on other travelers. Private vehicle owners choose to drive their vehicles instead of utilizing other transportation modes because of the private cost that it incurs on them. Every traveler values their time, vehicle expenses, such as gas, maintenance, and roadway tolls, convenience at a different rate. Users who value their monetary assets more or live in locations easily accessible to public transit are more likely to utilize that mode. Users who value control and convenience are more likely to drive their own vehicles. Each vehicle that 
enters a roadway only feels the average cost and delay that is incurred from all road users, which sets drivers' private cost equal to social cost. There are no thoughts of marginal social cost and the additional expenses and time delays imposed on others with the addition of each individual vehicle, which is what leads to congested roadways.

With the increased vehicle mix occupying school zones today, mode choice and congestion have become important issues. Buses and private vehicles are often battling one another for school access during limited arrival and dismissal periods, leading to unforeseen amounts of congestion. In order to lessen this congestion, drivers must be made aware of their actions and educated on their role in school zone traffic flow operations.

\subsection{1: Traffic Flow Operations}

Traffic flow procedures in school zones are primarily limited to the pick-up and drop-off operations at a school site. These operations vary between school sites, causing confusion among drivers and adding to congestion. Due to the standard 8:00 AM - 3:00 PM school day, congestion in school zones is typically only an issue during morning arrival and afternoon dismissal times. Due to the variance of afternoon pick-up times, this period characteristically experiences less dense congestion than its morning counterpart; however, the duration of afternoon/evening congestion lasts much longer. The start of parents' workdays often coincides with the start of school, causing this morning arrival time to be heavily congested (Woolridge 2003). The staggered arrival and presence of multiple transportation modes, in particular the high frequency of private vehicles, adds to the confusion already associated with traffic flow operations within school zones. Further complicating matters for drivers is the fact that school

zone speed limits not only vary from state to state, but in some cases also from school to school. 
The lack of consistency for drivers increases their confusion and ultimately creates more congestion.

Student age can also impact traffic operations within school zones. The most supervised loading/unloading zones are typically at elementary schools, whereas high schools often have limited instruction within those areas (Woolridge 2003). This can be attributed to the amount of responsibility assigned to children of those ages. Many high school students drive themselves to school and have strong knowledge of their expectations during highly congested arrival and dismissal times. In the case of elementary schools, traffic flow procedures may be gone over and explained to students, but their lack of participation and interest in the process makes it unlikely that they would communicate these expectations to parents who are the ones traversing the zone.

Many schools utilize traffic control devices to communicate with drivers. Various types of traffic control devices often utilized in school zones are discussed in section 1.2.1 of this report. However, despite the installation of these communicative measures, the use of these devices is often poorly executed. In one study in California, the average device was non-standard in compliance with MUTCD, misused, or worn-out. Even in cases where devices were being implemented properly, parents frequently ignored the devices, which could be a result of lack of knowledge or awareness (Woolridge 2003). In order to properly employ traffic control devices, drivers must be aware of their presence and purpose. Communication with drivers needs to be implemented before drivers are faced with the actual act of driving through a school zone.

\subsection{2: Case Studies}

Various types of traffic studies have been conducted to determine the best approach to managing congestion within school zones. Many of these studies were conducted by local authorities and 
lack a variety of sites; however, their findings are all compatible. For example, a study in Plano, Texas by the neighborhood police department, while conducted at only one school by a nonengineering organization, is a solid example of improving traffic flow and increasing safety in congested school zones in similar situations and locations. The area surrounding Plano had experienced significant population growth, while the neighborhood housing the school did not adapt its infrastructure to the increased access need and traffic flow. As a result, the school zone was constantly congested during school hours, leading to increased traffic violations, crashes, and decreased overall safety for everyone present, especially children. Initially, the police department dealt with these incidents individually; however, it became evident that addressing the overall issue of traffic design and flow would be more beneficial in eliminating and reducing many of the problems. Working with traffic engineering professionals, the Plano Police Department made the following changes: defined specific instructions on carpool lane operations, clearly marked no parking zones, increased the number and visibility of crosswalks, and synchronized traffic lights with school dismissal. In addition, the police department outlined alternate traffic routes throughout the neighborhood, distributed flyers to parents outlining these changes, and increased law enforcement. The most elaborate countermeasure was the construction of a new parking lot and access road leading to the main arterial and a new intersection onto that road. The intersection designed was a Y-intersection, in order to allow quick access onto the main arterial and discourage thru traffic from using the school zone neighborhood as a shortcut. In conclusion, through public surveys and observation, it was determined that by making these changes, the same traffic volume experienced a much more efficient and safer traffic flow (Nors 2004). 
Another report written by the Police Department of Irvine, CA aimed to display the effects of certain traffic implementations and community efforts in school zone traffic management. Irvine is a master planned community containing both urban and rural areas and contains four major freeways. School zone traffic safety and congestion has been a problem in numerous public schools in Irvine over the past ten years due to an increased vehicle mix attempting to access inadequate infrastructure around schools during arrival and dismissal times while operating in a hurried state. Previous attempts to address these issues were dealt with on an individual basis by different organizations, but it was discovered that the one-dimensional approach was inadequate. Therefore, the Irvine Police Department organized an initiative to address these problems as a whole by incorporating various disciplines in the decision making process. School administrations, law enforcement officials, traffic engineers, and numerous other community members were included in this process. To begin, one school was selected and problems were identified. Once addressed, tasks were assigned to the appropriate organization and then implemented. After application and review it was discovered that by utilizing appropriate signage, organizing specific drop-off/pick-up procedures, designating crosswalks and informing all involved parties (parents, faculty, students, general public) of these changes, congestion was reduced and safety was increased. These solutions were then applied as necessary to other school zones in the surrounding area with similar successful results. Because of the uniformity of these measures, compliance was achieved much quicker at each new site due to the public's awareness of operation from experience in other school zones. Thus, it can be concluded that the involvement of multidisciplinary teams in the planning process of school zone traffic management and the uniformity of solutions across unique sites is imperative in a successful application. (Jenner 1999). 
There are a number of countermeasures that can be applied to school zone traffic operations in order to reduce the effects of congestion. It has been observed that a separation of traffic modes, such as separate and specific loading and unloading areas for school buses and private vehicles, leads to a safer environment and eliminates conflict points and vehicle-pedestrian interaction. In addition, a structured arrival and dismissal procedure for both parents and students is necessary to maintain an organized school zone traffic flow and ease congestion. Moreover, there is no observed consistency between schools' operations and, in many cases, no instruction whatsoever. Schools need to make an effort to organize and supervise loading/unloading zones in order to increase efficiency and safety in these areas (Woolridge 2003). Perhaps the best ways to achieve this consistency is to increase the involvement of transportation professionals in school site planning, and, except where necessary, remove traffic flow interrupters. It is also beneficial to precede traffic changes and device installations with traffic engineering analysis and provide alternate truck routes around school zones. In most cases, preventative measures are the most effective, but unfortunately, they are the least enforced (Wells 1977).

Potentially, the most effective solution would be to establish a school transportation safety committee at either an individual school or district level. This committee would devote time to addressing complaints, common violations and safety concerns. The committee would consist of a diverse group of members including traffic engineers, principals, parents, police, maintenance employees, and student safety patrol representative. For maximized effectiveness, the group should meet frequently and maintain regular contact with parents through a newsletter or other similar correspondence. Establishing communication with parents and students regarding their expectations is a vital and often ignored aspect of school zone traffic flow procedures. Ironically, in most instances, parents were the main violator. Children, especially elementary school aged, 
tend to follow the example set by their parents, thus, their cooperation in proper school zone procedures is essential. By informing and educating parents on proper safety school zone practices, many conflicts can be avoided (Isebrands 2007).

Preventative action and education is best achieved through the implementation of public awareness campaigns. It takes a unique combination of programs to address issues at each location. The probability of successful implementation is more likely when programs address the public's concerns, adapt to driver's behavior instead of attempting to change it, and create an incentive for involved parties to desire successful results. Certain obstacles in successful application include the fact that it is not the school's mission to reduce or address traffic congestion, and there are few incentives or requirements in place to increase its importance. Another issue is poor site selection of schools in relation to potential traffic issues. Also, programs designed to encourage students to walk to school are focused mainly on increasing physical fitness and increasing safety, not addressing transportation issues. In conclusion, it is recommended that states set targets for schools to reduce auto use and increase walking and biking frequency. To ensure increased compliance, incentives should be created to reward schools who meet these targets and provide increased incentives for schools located in pedestrian friendly and uncongested sites. In addition, Safe Routes to Schools and similar programs should broaden their scope to include transportation efficiency goals (Carlson 2009).

In order to reduce congestion in school zones, the best strategies include the separation of transportation modes, creation of uniform traffic flow procedures throughout school districts, increased supervision and enforcement of these procedures and parent involvement and cooperation through the creation of multidisciplinary teams and public awareness campaigns. 
The objective of creating a less congested school zone is best achieved through the incorporation of law enforcement, uniformity, awareness and education into school zone traffic operations.

\section{5: West Virginia School Zones}

West Virginia school zones experience all of the issues discussed in previous sections in varying degrees. Matters of vehicle speed, congestion and mode choice differ depending on school site location, with urban schools experiencing higher levels of congestion and rural schools experiencing higher vehicle speeds. Despite the differences in dominating concerns, all schools are aware of and focused on improving safety and efficiency within their zones.

School zones are considered speed zones. According to a 2003 Traffic Engineering Directive issued by the West Virginia Department of Highways (WVDOH), a speed zone can only be established on the basis of an engineering study that has been performed in accordance with traffic engineering practices. The study should include an analysis of current speed distribution of free-flowing vehicles. A school zone in West Virginia is defined as any section of noncontrolled access highway abutting a school or school grounds and extending 125 feet in either direction of the school. The school can be either public or private, but must be recognized by the state education authority for one or more grades, kindergarten through twelfth grade, or as otherwise defined by the state. West Virginia Division of Highway is the regulatory agency for the school zones in the state. The WVDOH is responsible for identifying school zones and advising the Board of Educations or State Department of Education on all traffic related issues.

The beginning and end points of the designated school zone must be marked except in three specific special cases: the school is adjacent to a highway; there is no crossing involved within the zone; or the speed limit remains unchanged. The speed limit in all West Virginia school zones is 15 miles per hour during school recess or while children are going to or leaving school 
during opening or closing hours. This speed restriction does not apply to vehicles traveling on a controlled-access highway which is separated from the school or school grounds by a fence or barrier approved by the division of highways (WV DOH 2003).

All signs used in school zones must be reflectorized or illuminated in order to remain visible to drivers in various weather and lighting conditions. In addition, signs must have a fluorescent yellow-green background with a black legend and border and must be located on the right-hand side of the roadway. The signs serve as warning and regulatory devices to drivers and are uniformly applied to all zones, regardless of location. The first sign a driver encounters on approaching a school zone is the School Advance Warning. As the name indicates, it warns drivers of the impending school area. It is used in advance of all school zones abutting a noncontrolled access highway and is installed within 150 to 700 feet from the School Speed Limit sign. The School Speed Limit sign reads 15 miles per hour in all West Virginia school zones and is installed in each direction of the zone approximately 125 feet from the property line of the school. The last sign a driver encounters within a West Virginia school zone is the End School Zone sign. It is installed at the end of the school zone across from the School Speed Limit sign. Figure 2.5-1 illustrates a typical school zone sign set-up. 


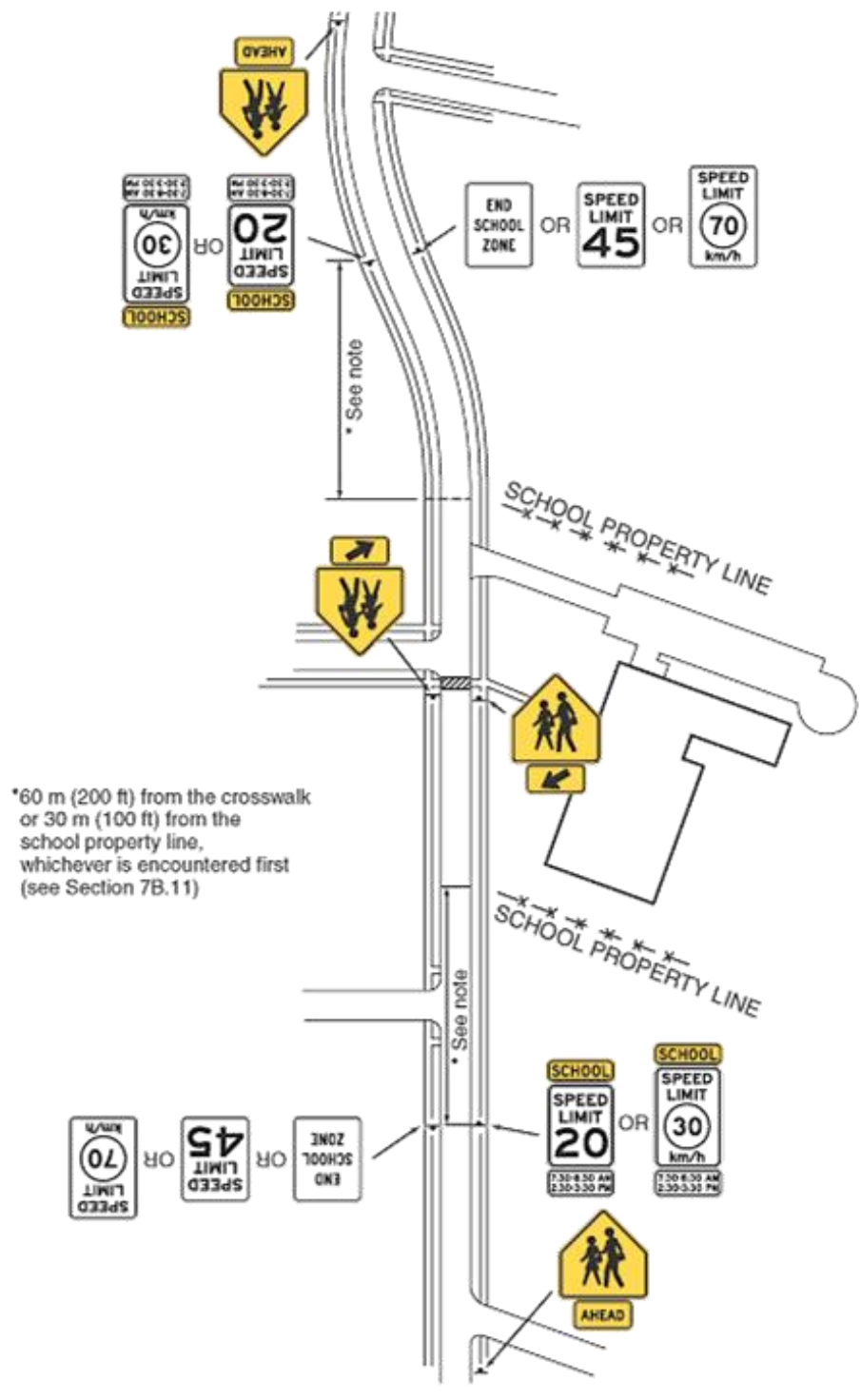

Figure 2.5-1: School Zone Signage Diagram

(http://mutcd.fhwa.dot.gov/htm/2009/part7/part7b.htm\#section7B09)

Flashing beacons are sometimes used to supplement the School Speed Limit, School Advance Warning and School Crossing Warning Assembly signs. Upon the installation of flashing beacons, "When children are present" messages are removed from the School Speed Limit sign and a "When flashing" message or plaque is mounted in its place below the School Speed Limit Sign. If utilized, flashing beacons must be uniformly installed on all approaches to the school. 
The WVDOH will provide the necessary beacon signs and permits for installation, but purchasing and installing flashing beacons is the responsibility of the school board, school officials, municipality, or local government agency.

Pavement markings are also used to communicate with roadway users within school zones. They can be used to supplement the regulations or warnings of other devices or alone to produce otherwise unattainable results. They are advantageous in that they can convey warnings or information without drawing drivers' attention away from the road; however, pavement markings experience some limitations avoided by other regulatory devices. They can be obscured by snow, not clearly visible when wet, and fade under heavy traffic flows. A specific type of pavement marking is a school crosswalk. Crosswalks are used to heighten the safety of students crossing streets at busy intersections or roadways. In order to install a crosswalk, the location must meet school crossing criteria. The frequency of gaps in the traffic stream must be sufficient for student crossing in addition to availability to an adequate number of sidewalks, an appropriate age and number of students that would use the crossing, and the total extra walking distance the crossing would add to a walking route.

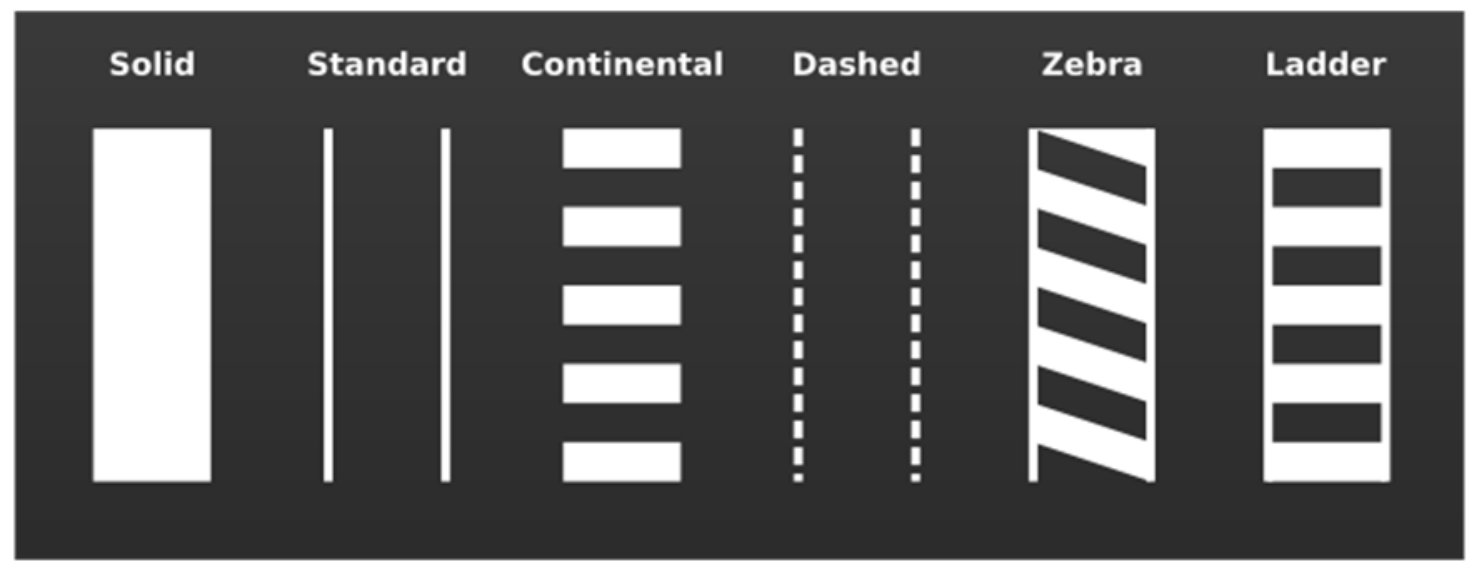

Figure 2.5-2: Crosswalk Pavement Markings 
Figure 2.5-2 shows the various pavement marking patterns available for use at an established school crossing. The crosswalk is accompanied by school crossing control. It is located only where sight distance is adequate in advance of the crosswalk. This sight distance is necessary so that drivers can bring their cars to a safe stop before reaching the crossing. Signing treatment at crossings is dependent on its location relative to an existing school zone. Crosswalks within school zones are often provided with crossing supervision. This supervision can range from student control of pedestrians to law enforcement officers' control of both pedestrians and vehicles. Adult crossing guards can control pedestrians and vehicles if they meet certain qualifications. They use a "stop" paddle to direct roadway users and provide gaps in traffic for pedestrians to utilize the crossing.

All school zones have a mandatory 15 mile per hour speed limit in West Virginia. Speed limits along all West Virginia roadways are established as outlined in Table 2.5-1.

Table 2.5-1: West Virginia Speed Limit Statutes (http://www.legis.state.wv.us/wvcode/code.cfm?chap=17c\&art=6)

\begin{tabular}{|l|l|}
\hline Speed Limit & \multicolumn{1}{c|}{ Roadway Characteristics } \\
\hline $255 \mathrm{mph}$ & Controlled-access highways \\
\cline { 2 - 3 } & Interstate highways \\
\hline $55 \mathrm{mph}$ & Open country highways \\
\hline $25 \mathrm{mph}$ & Business and residential districts \\
\hline $15 \mathrm{mph}$ & School zones \\
\hline
\end{tabular}

When schools are located within business and residential districts, this speed reduction is practical. The minimal reduction required of vehicles leads to high compliance rates. However, in schools located along open country highways, the sudden 20 mile per hour reduction required 
of drivers is unexpected and often disregarded by drivers due to inconvenience or obliviousness. Further complicating matters is that school zone speeds are only in effect during school recess or "while children are present." Without the presence of flashing beacons, there is little communication to drivers as to whether students are present and what speed is in effect.

Table 2.5-2: West Virginia Speed Limit Violation Penalties (http://www.legis.state.wv.us/wvcode/code.cfm?chap=17c\&art=6)

\begin{tabular}{|c|c|c|c|}
\hline Speed Law Violation & Exception & Imprisonment & $\begin{array}{l}\text { Mandatory } \\
\text { Minimum Fine }\end{array}$ \\
\hline \multirow{3}{*}{$\begin{array}{l}\text { Basic speed rule violation or } \\
\text { exceeding speed limit }\end{array}$} & \multirow{3}{*}{$\begin{array}{l}3^{\text {rd }} \text { or subsequent offense } \\
\text { (within two years) } \\
\text { exceeded speed limit by } \\
\geq 15 \mathrm{mph}\end{array}$} & \multirow{3}{*}{$\leq 6$ months } & $1^{\text {st }}$ offense: $\leq \$ 100$ \\
\hline & & & $\begin{array}{l}2^{\text {nd }} \text { offense (within } \\
\text { one year): } \leq \$ 200\end{array}$ \\
\hline & & & $\begin{array}{l}3^{\text {rd }} \text { or subsequent } \\
\text { offense (within two } \\
\text { years): } \leq \$ 500\end{array}$ \\
\hline Speeding in a school zone & $\begin{array}{l}\text { Exceeding the speed } \\
\text { limit by } \geq 15 \text { mph when } \\
\text { one or more children are } \\
\text { in school zone }\end{array}$ & $\leq 6$ months & $\$ 100-\$ 500$ \\
\hline $\begin{array}{l}\text { Speeding in a construction } \\
\text { zone }\end{array}$ & & & $\leq \$ 200$ \\
\hline
\end{tabular}

It is evident from Table 2.5-2 that speeding in a school zone is considered a more serious offense than other speeding instances due to its mandatory minimum fine of $\$ 100$, while other speeding infractions could result in no fine. Speeding in a school zone will result in a fine and could result in imprisonment on the first offense, whereas these penalties are only applicable to recurring offenders in other speeding instances. 


\subsection{1: Comparison to Other States}

Throughout the United States, there are five categories of school zone speeds. Some states have no school zone speed limits while others have multiple limits assigned at each individual school's discretion. The states which have statewide mandatory speeds vary from $15 \mathrm{mph}$ to 25 mph. Figure 2.5-3 illustrates school zone speed limit laws across the United States

Figure 2.5-3: United States School Zone Speed Limit Distribution

\begin{tabular}{|l|l|l|l|l|}
\hline $15 \mathrm{mph}$ & $20 \mathrm{mph}$ & $25 \mathrm{mph}$ & Multiple & None \\
\hline
\end{tabular}

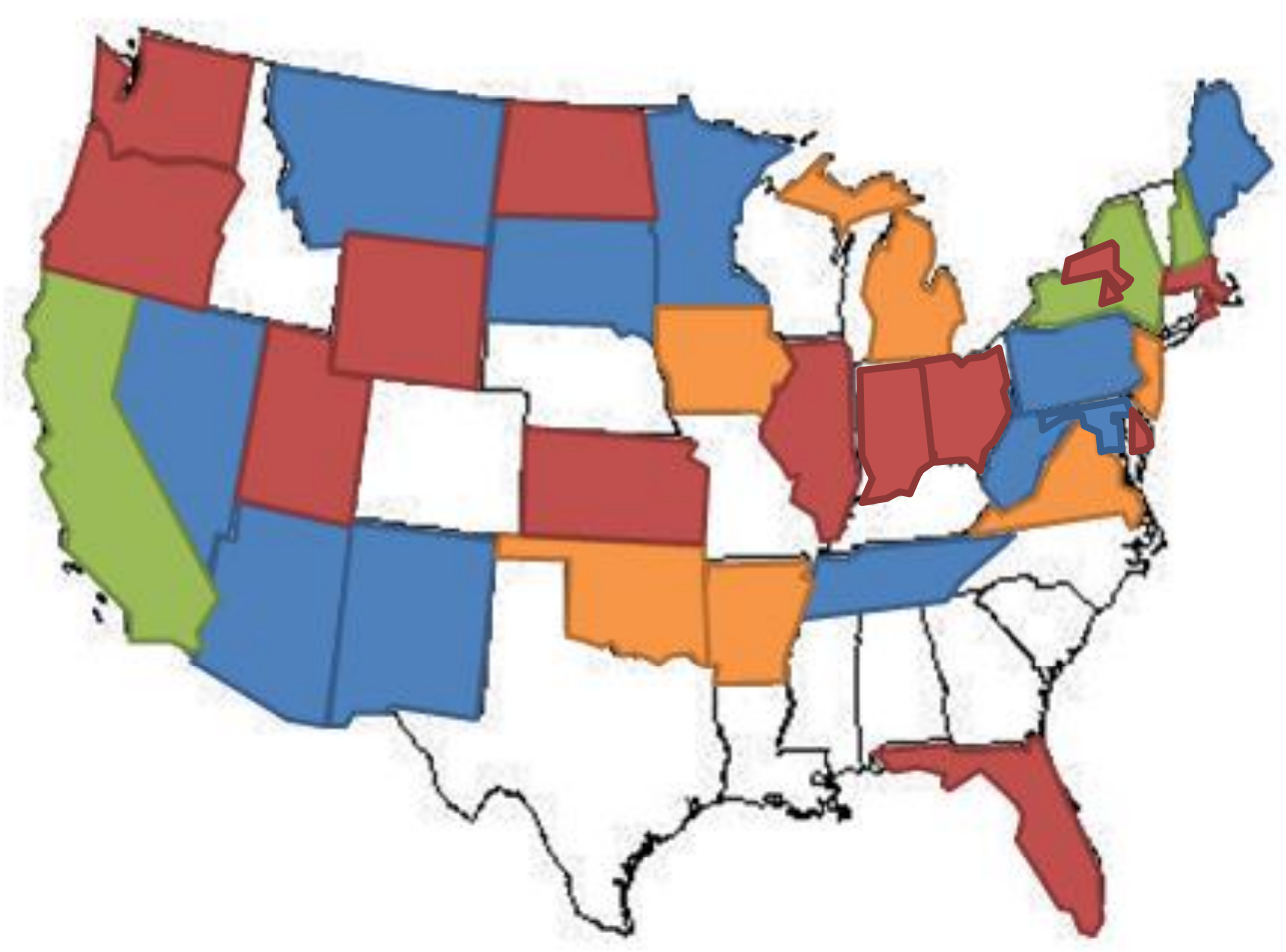

As shown in Figure 2.5-3, fifteen states, including Hawaii, have no designated school zone speed limit, while there are twelve states and Washington D.C. with a $15 \mathrm{mph}$ school zone speed limit, the lowest in the United States. West Virginia is among these thirteen. Fourteen states, including Alaska, have $20 \mathrm{mph}$ school zone speed limits, and 3 have multiple school zone speed limits. 
The states with multiple school zone speed limits are California, New York and New Hampshire. California and New York rank in the top three among state population; therefore, they likely have a large number of urban school zones. Schools in large cities such as New York or Los Angeles should not be treated as equals with schools in rural settings, and California and New York have recognized this discrepancy and set their school speed limits at a limit adaptable to both location types. New Hampshire, on the other hand, ranks $42^{\text {nd }}$ in population among the United States and unlikely experiences the drastic variance of school zone type that more densely populated states would. It is likely that New Hampshire adopted similar laws to New York due to its proximity or more flexible state speed legislation.

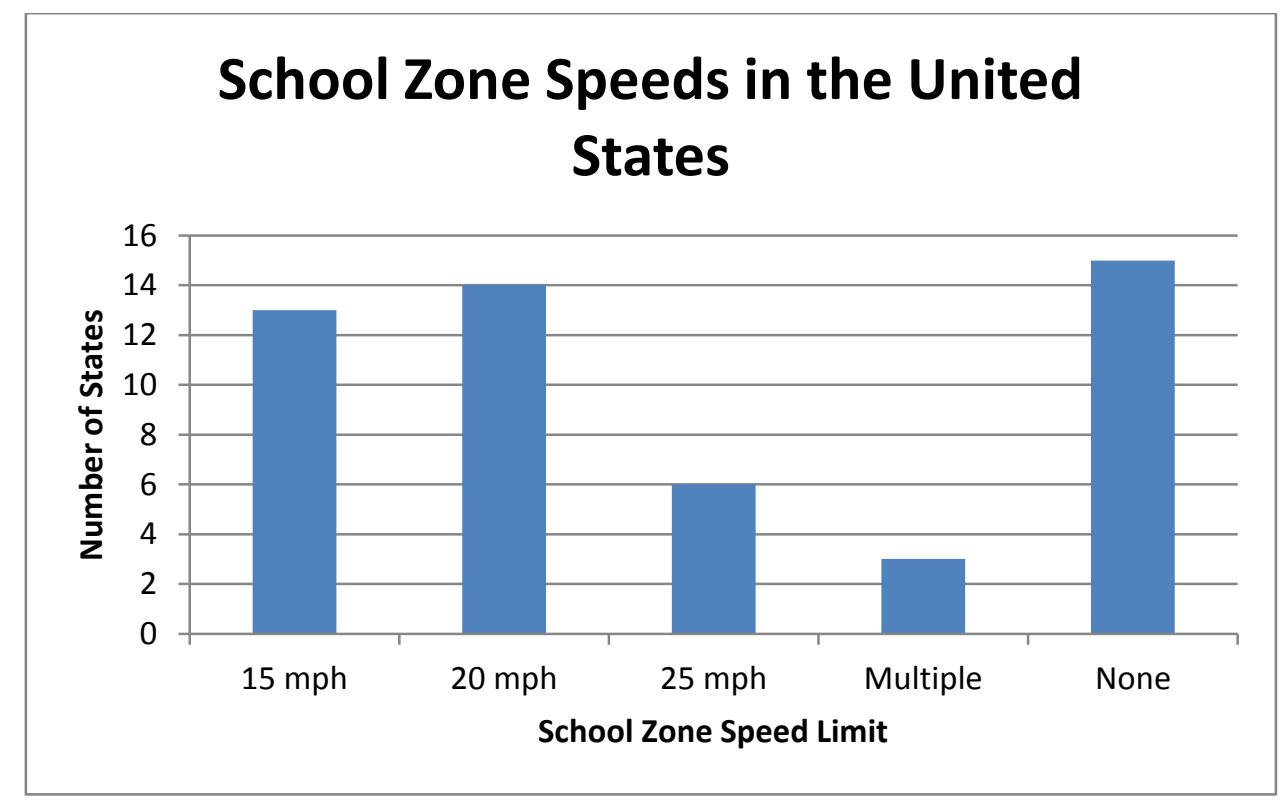

Figure 2.5-4: United States School Zone Speed Limits

The highest statewide school zone speed limit is $25 \mathrm{mph}$ and is located in Arkansas, Iowa, Michigan, New Jersey, Oklahoma and Virginia. Michigan, New Jersey, and Virginia fall on the higher end of state population ranking $9^{\text {th }}, 11^{\text {th }}$, and $12^{\text {th }}$ respectively. Oklahoma, Iowa, and Arkansas fall in the middle of state population ranking $28^{\text {th }}, 30^{\text {th }}$ and $32^{\text {nd }}$ respectively. 
Table 2.5-3: United States School Zone Speed Limit vs. Population

\begin{tabular}{|c|c|c|c|c|}
\hline & \multirow{2}{*}{$\begin{array}{c}\text { State School } \\
\text { Zone Speed } \\
\text { Limit }\end{array}$} & \multicolumn{3}{|c|}{ Population Rank } \\
\hline & & $\begin{array}{l}\text { Top Third } \\
\text { (1st - 17th) }\end{array}$ & $\begin{array}{l}\text { Middle Third } \\
\text { (18th - 34th) }\end{array}$ & $\begin{array}{c}\text { Bottom Third } \\
\text { (35th - 51st) }\end{array}$ \\
\hline \multirow{5}{*}{$\begin{array}{c}\text { Number } \\
\text { of } \\
\text { States }\end{array}$} & $15 \mathrm{mph}$ & 3 & 3 & 7 \\
\hline & $20 \mathrm{mph}$ & 6 & 3 & 5 \\
\hline & $25 \mathrm{mph}$ & 3 & 3 & 0 \\
\hline & Multiple & 2 & 0 & 1 \\
\hline & None & 3 & 8 & 4 \\
\hline
\end{tabular}

Table 2.5-3 shows the distribution of state school zone speeds in relation to their population rank nationwide. Among states with the highest population, majority have $20 \mathrm{mph}$ school zone speed limits, while states with the lowest population most often have $15 \mathrm{mph}$ school zone speed limits. States that fall in the middle of statewide population most often have no statewide school zone speed limit mandate. States in the bottom third of state population have no states with $25 \mathrm{mph}$ school zone speed limits and only four with no school zone speed limit regulation. The presence of lower speed limits in more rural states is likely attributed to the high occurrence of speeding in these locations. States in the middle of the population rankings have the highest frequency of states with no statewide school speed limit. This is likely due to the fact that these states have a wide variety of school zone types ranging from urban to rural and realize the need to designate school zone speed limits on a case-by-case basis. The most heavily populated states most likely have higher school zone speed limits because they are more concerned with congestion than other states. Schools' presence in urban settings means that speed limits are already low and drivers are unable to speed; therefore, higher school zone speed limits are set in order to move traffic more quickly and alleviate congestion. 
As urban sprawl continues to cause population growth and school consolidation in West

Virginia, school locations are becoming more and more varied throughout the state. The

statewide, one-size-fits-all school zone speed limit may no longer be practical, and in some cases unsafe. Drastic speed reductions along roadways are likely to lead to an increased number of crashes and introduce another safety hazard. The successful implementation of 20 or $25 \mathrm{mph}$ school zone speed limits and multiple school zone speed limits throughout many states can serve as guidelines for updating and adapting West Virginia school zone speed limits.

\section{6: Literature Review Summary}

Throughout review of the literature on school zones, it is evident that the two primary areas of concern are safety and efficiency. It is also evident that the two are often treated as separate issues when, in fact, they can be addressed concurrently. Another issue is that safety is often emphasized over efficiency, causing efficiency issues such as congestion and vehicle mix to be neglected. What goes unrealized is that by neglecting to address efficiency issues within a school zone, the safety of that site is also compromised. Safety and efficiency are directly related and it is impossible to improve one while ignoring the other.

Across the findings of numerous studies, some implementation strategies are recurrent. There is a need for standards and uniformity. Traffic control is achieved most effectively through the uniform application of realistic policies, practices and standards. Education on these procedures is also imperative to the successful improvement of school zone operations. Education should not be limited to students; instead, it should be accessible to all drivers utilizing a school zone. Education is needed for public understanding of both pedestrian and driver knowledge of their responsibilities within a school zone. 
Another proven component of successful school zone traffic control procedures is uniformity. A lack of uniform procedures and devices causes confusion among both pedestrians and drivers, prompting inappropriate decisions and contributing to crashes. The best way to achieve this uniformity is to treat comparable traffic situations in a consistent manner and to utilize each traffic control device and control method for a specific function under a specific condition. This application assures the use of similar controls for similar situations across all school zones and promotes appropriate and uniform behavior by all road users.

Through a combination of safety and efficiency goals, school zone operation improvement is a realistic accomplishment. Incorporating multidisciplinary cooperation in determining traffic issues and solutions will create more comprehensive solutions and help address issues in a preventative manner. One of the most cost effective and advantageous way to achieve school zone improvement is through public awareness campaigns. These campaigns encompass virtually all implementation techniques by educating the public in a uniform manner about the incentives associated with improved school zone operations. 
A variety of approaches were used to address the objectives and scope of this project. Through a combination of research, survey development and distribution, and school zone crash data analysis each of the parameters outlined in the problem statement were addressed. Examining current warrants and laws relevant to school zones in West Virginia and other states was addressed in the literature review. Research into current school zone laws in all states was performed with particular emphasis on practices in West Virginia relative to other states. At the same time, traffic safety and congestion problems in school zones in general were investigated. An overview of the main issues associated with both safety and congestion are discussed in greater detail in the literature review section of this report. In order to determine what specific safety and efficiency issues plague West Virginia school zones, surveys were created to poll a random sample of transportation officials, superintendents, and district engineers throughout the state.

\section{1: Survey Development and Distribution}

A brief survey was administered at the county level amongst school transportation officials and superintendents, and a similar survey was conducted at the district level amongst district or traffic engineers throughout West Virginia. School transportation officials were mainly country transportation directors or supervisors, with the actual job title varying between counties. In cases where transportation directors were unavailable or nonexistent, county superintendents were contacted. These short questionnaires were administered over the phone in order to gain a better understanding of the efficiency and safety of current traffic operations within school zones across West Virginia and how they vary by region. The focus of the survey was to identify dominant safety concerns of transportation officials by contacting those holding positions with 
the most influence and exposure to school transportation procedures. Questions were mainly targeted at confirming student mode choice and potential traffic flow improvement options.

\section{Generation of Survey Questions}

The creation of survey questions began with a comprehensive list of issues discovered throughout the research conducted during the literature review. These issues were organized by area of emphasis with the main focuses being safety and efficiency. Topics included vehicle congestion, vehicle mix, vehicle speed, compliance, weather, and traffic flow procedures.

A broad list of open-ended questions was then generated in order to attempt to address these issues in as few questions as possible while targeting specific issues. These questions probed into areas of concern and variation among school type, school zone procedure uniformity and awareness, enforcement, mode choice with an emphasis on walking and feasibility, and Safe Routes to School involvement and awareness. In order to encourage that specific issues were addressed, questions were then edited to a multiple choice/fill-in-the-blank format. A choice of particular concerns, solutions, policies, and mode choices were provided for each question, and then used to reformat the survey.

The survey was further modified to condense the questionnaire into five questions. Each question was designed to be easily administered and filled-out over the phone. In order to reduce confusion, and allow for convenient response analysis, answers were clearly outlined for each question as either a choice selection, ranking or short fill in the blank. To aid in easily cataloging responses, a section for contact information and survey date and time were provided. The final survey is available in Appendix A. The district survey is essentially the same version as the 
county survey, with only question wording adjusted to address district level issues rather than county level.

\section{2: Highway Safety Information System Data}

While the school zone survey provided insight into the issues facing schools in West Virginia, they were limited in that they were from the viewpoint of transportation and county officials throughout the state and did not provide insights into actual school zone crash information. In order to gain a better understanding of what causes school zone crashes and the attributes of the crashes and environment, further data analysis was performed. Since no school zone crash data is available for West Virginia, the Highway Safety Information System provided crash data for the analysis performed in the report.

\section{Data Acquisition}

The data used was provided by the Highway Safety Information System (HSIS), an online database that contains roadway, crash, vehicle, and occupant data for certain states. It is managed by the University of North Carolina Highway Safety Research Center (HSRC) under contract with FHWA. Active participating states include California, Illinois, Maine, Minnesota, North Carolina, Ohio, and Washington. Only Ohio and North Carolina data was used in this report. Data from all reported school zone crashes between 2006 and 2010 was included for specific data variables since for safety research, typically three to five years is sufficient for significant results. 


\section{Data Analysis}

Data was initially contained in separate files for roadway, crash, vehicle and occupant variables with separate files for each year. In order to run regressions and compare variables, a combined database was created which contained all variables for all available years.

The original data files contained all crashes in each state for the five selected years. In order to separate school zone crashes, a special area code variable (SCH_WZON for Ohio and TRF_CNTL for North Carolina) was used to select only those crashes which occurred in a school zone. These data points were labeled with a 2 in the SCH_WZON category and labeled with an 11 in the TRF_CNTL category to indicate the presence of a school zone. This data was then further combined using linkage variables present in the separate crash, roadway, vehicle and occupant data files.

The vehicle, accident, and occupant files all contained a common case number that was used to properly join the data for each case. The data was identified using a county route number variable which was also present in the accident data file and was used similarly to the case number variable in matching up roadway data with crash data.

Once the data was combined into a single file, the variables were further analyzed to determine their necessity and significance. Some variables were eliminated due to repetition among files or insufficient data collection among all crashes. Once all unnecessary variables were removed and the data reorganized, the file was then imported into $\mathrm{R}$ studio for statistical analysis.

Within R studio various statistical analyses were performed. Frequency tables were generated for categorical variables to gain understanding about the crash characteristics making up the majority of crashes within school zones. For numerical variables, descriptive statistics were 
formulated to understand the spread and trends among crash characteristics such as driver age and vehicle speed at the time of a crash. Variables were coded using HSIS requirements and were recoded as necessary to adapt to the needs of this analysis. Some numerical variables were also converted into categorical variables to better interpret and compare data.

Cross tabulations were then generated in order to compare certain variables to one another. These cross tabulations provided a general idea about the selected variables and used to make some insights about the comprehension of school zone crashes in Ohio and North Carolina from 2006 to 2010. 


\section{0: Findings}

\section{1: Survey Findings}

The survey discussed in section 3.0 of this report was conducted over the phone to a random selection of county transportation officials and superintendents along with district engineers. Once enough survey responses were garnered, the results were compared in order to identify common issues across each region and to determine conflicting operations across all school zones that could be confusing to drivers or students and hinder the safety of school zones.

Transportation officials' responses were compatible at both the county and district levels. The preferred improvements were increased penalties for traffic violations within a school zone and a reduced speed for drivers. Their other options included uniformity in school zone procedures and public awareness campaigns.

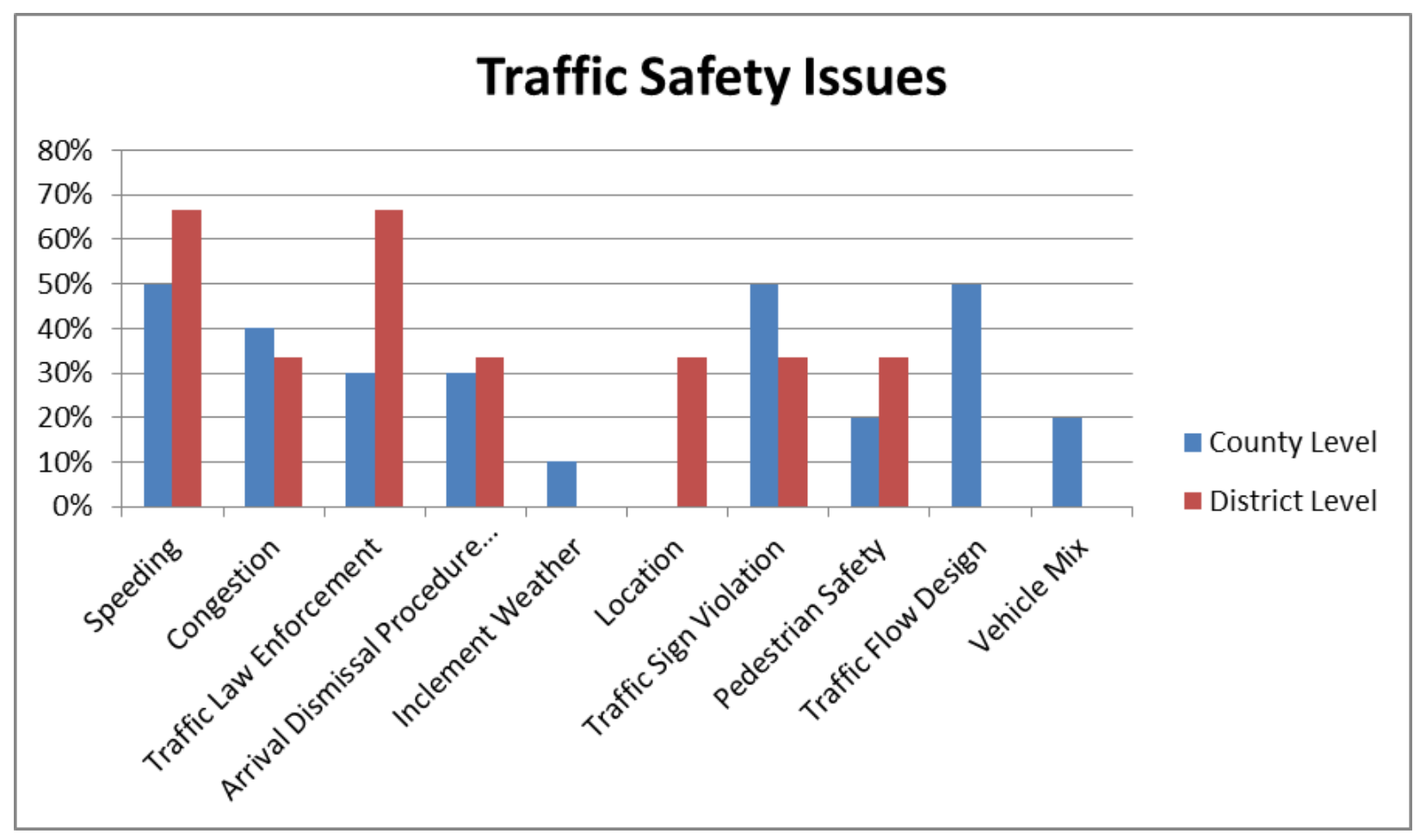

Figure 4.1-1: Survey Issue Results 
Figure 4.1-1 depicts the perceived school zone safety issues and the percentage assigned to their importance within operating a safe school zone. As is shown, speeding, traffic sign violation, and traffic flow design were the main areas of concern at the county level, while speeding and traffic law enforcement were the focus at the district level. Congestion was also a concern, but not emphasized as strongly as the other issues which could be attributed to the fact that congestion is not often considered a safety issue.

Congestion is more commonly identified as an efficiency issue; however, the two are not mutually exclusive. The safety of a school zone, or any traffic operation, is directly impacted by its efficiency and vice versa. The more quickly drivers react to changes in traffic flow and the more efficiently that they move through the zone, the safer that zone becomes. This efficiency is driven by driver knowledge and expectation of what they will be faced with within the zone which is where public awareness campaigns and driver education are introduced. Unfortunately the connection between safety, efficiency and driver knowledge is not always made, and certain solutions to school zone traffic operations are not even considered, let alone employed.

\section{County District}
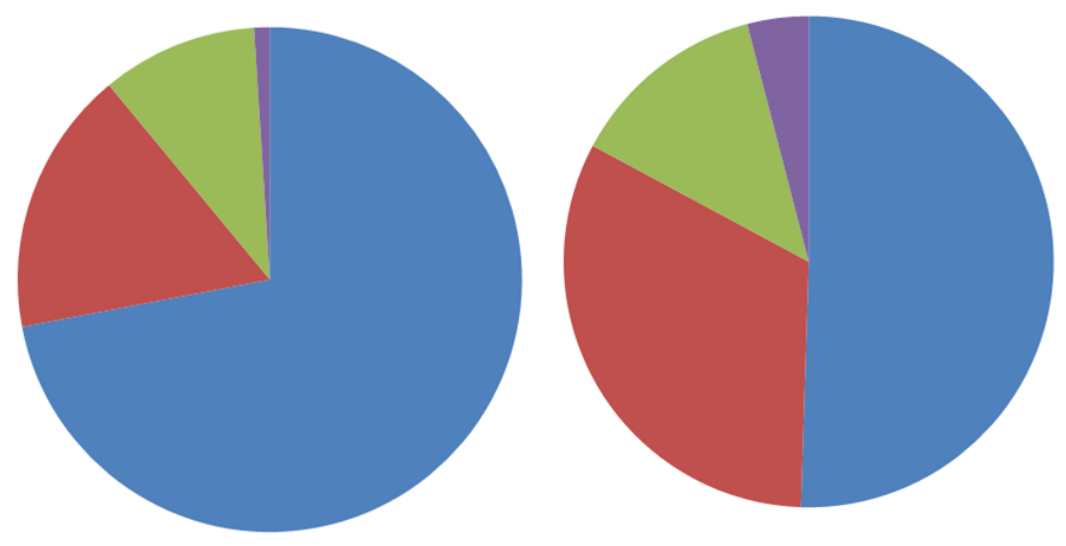

School Bus

Private Vehicle: Student Passenger

Private Vehicle: Student Driver

Figure 4.1-2: Student Mode Choice Comparison 
Figure 4.1-2 depicts the frequency of mode choice by students according to either the superintendent or transportation director at the county level and by the traffic or district engineer at the district level. Percentages of mode vary slightly between district and county, but the order remains the same. Transport by school bus is by far the most utilized form of student transport followed strongly by private vehicle where the student is the passenger, then private vehicle where the student is the driver. Walking and/or biking are practically non-existent within student mode choice. The increasing percentage of private vehicles into the school zone traffic operation procedures has introduced many of the issues outlined in Figure 4.1-1. Higher frequency of vehicles leads to increased congestion, driver distraction, driver confusion, and ultimately traffic violations or crashes.

\section{2: HSIS Findings}

\subsection{1: Ohio}

In this section, insights specific to school zone crashes in Ohio are outlined using the descriptive statistics generated during the data analysis process explained in the above section. From 2006 to 2010 there were 424 school zone related crashes with 682 drivers and 394 occupants.

Table 4.2-1 indicates that the majority of vehicles involved in school zone crashes are travelling at $15 \mathrm{mph}$ with a maximum recorded travel speed of $65 \mathrm{mph}$ and a third quartile speed of $20 \mathrm{mph}$ and only 19 of 639 vehicles traveling above $40 \mathrm{mph}$. These speeds correspond with majority of posted speed limits at $20 \mathrm{mph}$, which is the required school zone speed limit in Ohio. Crash location is most frequently along urban two lane roads with average speed limit between 25 and $35 \mathrm{mph}$. For this study, vehicle speed does not appear to be a major contributing factor to crashes in school zones; therefore, it can be concluded that most vehicles involved in school zone crashes are obeying posted speed limits and compliance is not an issue. 
Table 4.2-1: Ohio Speed Frequency

\begin{tabular}{|l|r|r|}
\hline \multicolumn{3}{|c|}{ Speed of Vehicle } \\
\hline Speed (mph) & Frequency & Relative Frequency \\
\hline Not Stated & 51 & $10.26 \%$ \\
\hline Under $20 \mathrm{mph}$ & 353 & $71.03 \%$ \\
\hline $21-30 \mathrm{mph}$ & 49 & $9.86 \%$ \\
\hline $31-40 \mathrm{mph}$ & 25 & $5.03 \%$ \\
\hline $41-50 \mathrm{mph}$ & 12 & $2.41 \%$ \\
\hline $51-60 \mathrm{mph}$ & 5 & $1.01 \%$ \\
\hline $61-70 \mathrm{mph}$ & 2 & $0.40 \%$ \\
\hline
\end{tabular}

The most common types of vehicle involved in school zone crashes in Ohio are passenger cars, followed by SUVs and pick-up trucks. There are very few other transportation modes involved in school zone crashes, including bikers and pedestrians. The distribution of male and female drivers is practically equal, as is their corresponding speed at time of impact with slightly more male drivers tending to drive slightly faster. As shown in Table 4.2-2, driver age ranged from 16 to 86 years old with a mean age of 35 and a median age of 34 years old, whereas occupant age ranged from 0 to 87 years old with a mean age of 28 and a median age of 20 years old. Thus, the age of occupants varies much more than the age of drivers; however, both categories are predominantly young. This is due to the presence of students and inexperienced student drivers.

The majority of drivers involved in crashes in school zones were between 16 and 18 years old, followed by $40-49$ year olds and 30 - 39 year olds. Again, this is attributed to the high presence of inexperienced student drivers and parent drivers. Through statistical analysis it was discovered that as driver age decreased, the likelihood that they were at fault increases. The most frequent age range of occupants involved in a school crash was $15-19$ year olds followed by $10-14$ year olds then $30-50$ year olds. This is attributed to the nature of school zone crashes and the 
overwhelming presence of younger students and their parents driving them and inexperienced student drivers. Most occupants were using proper safety equipment at time of crash and received no injury.

Table 4.2-2: Ohio Descriptive Statistics

\begin{tabular}{|l|r|r|r|r|r|}
\hline & \multicolumn{1}{|c|}{$\begin{array}{l}\text { Vehicle } \\
\text { Speed }\end{array}$} & \multicolumn{1}{c|}{$\begin{array}{c}\text { Posted } \\
\text { Speed Limit }\end{array}$} & Driver Age & \multicolumn{1}{c|}{$\begin{array}{c}\text { Number of } \\
\text { Vehicles }\end{array}$} & \multicolumn{1}{c|}{$\begin{array}{c}\text { Occupant } \\
\text { Age }\end{array}$} \\
\hline Min & 0 & 0 & 16 & 1 & 0 \\
\hline 1st Qu. & 5 & 20 & 18 & 2 & 16 \\
\hline Median & 15 & 20 & 34 & 2 & 20 \\
\hline Mean & 15.66 & 22.88 & 35.41 & 2.076 & 28.5 \\
\hline 3rd Qu. & 20 & 20 & 47 & 2 & 41 \\
\hline Max & 65 & 65 & 86 & 5 & 87 \\
\hline Variance & & 72.75112 & & 0.2288076 & \\
\hline $\begin{array}{l}\text { Std. } \\
\text { Dev. }\end{array}$ & & 8.529427 & & & \\
\hline
\end{tabular}

The most commonly recorded pre-crash action is movement straight ahead followed by slowing/stopped in traffic which leads to the high frequency of rear-end crashes and zero fatalities. In addition, the first action in the sequence of events within the crash is predominantly collision with a moving motor vehicle. Following too closely decreases steadily with age along with failure to control and other improper actions; however, improper lane change/driving off road is comparable across all age groups. The occurrence of this action regardless of age is likely attributed to a lack of education and awareness about this skill.

Due to the drastic increase of school zone traffic during school operating hours, the majority of school zone crashes occur during the week between 7:00am and 8:00 am. There is also a high frequency of crashes during 3:00pm and 4:00 pm, but significantly less than in the morning. This distribution is attributed to the staggered afternoon pick-up times due to extra-curricular activities and flexibility as opposed to the rigidity of morning drop-off times as there is less 
variance in the times available for parents to drop off their children. Majority of crashes occur during the week with slightly more on Mondays and Tuesdays, possibly as drivers readjust to the weekly routine after the weekend, and very few crashes occurred on the weekend or after 11:00pm.

The number of vehicles involved in a crash range from one to five with a mean, median, and mode of two; thus, the majority of crashes in school zones are one or two vehicle crashes. Due to slow speeds and the stop-and-go nature of drop-off and pick-up zones within school zones, these are mostly rear-end crashes with only property damage and no pedestrians involved; however there were eleven crashes involving pedestrians/bicyclists.

\subsection{2: North Carolina}

The following section highlights the results from the analysis of school zone crashes in North Carolina using the same process as the Ohio data analysis. From 2006 to 2010 there were 1023 school zone related crashes. Unfortunately there are no roadway inventory variables that specify whether or not a specific roadway segment lies within a school zone. Thus, we must use crashbased variables to identify the presence of a school zone.

Table 4.2-3: North Carolina Speed Frequency

\begin{tabular}{|l|r|r|}
\hline \multicolumn{3}{|c|}{ Speed of Vehicle } \\
\hline \multicolumn{1}{|c|}{ Speed (mph) } & Frequency & $\begin{array}{c}\text { Relative } \\
\text { Frequency }\end{array}$ \\
\hline$<20$ & 609 & $40.47 \%$ \\
\hline $21-30$ & 210 & $13.95 \%$ \\
\hline $31-40$ & 415 & $27.57 \%$ \\
\hline $41-50$ & 142 & $9.44 \%$ \\
\hline $51-60$ & 71 & $4.72 \%$ \\
\hline $61-70$ & 40 & $2.66 \%$ \\
\hline$>70$ & 18 & $1.20 \%$ \\
\hline
\end{tabular}


Table 4.2-3 indicates that vehicle speed at the time of crash ranged from $0 \mathrm{mph}$ to $100 \mathrm{mph}$ with mean speed of $27 \mathrm{mph}$. Since third quartile speed is only $35 \mathrm{mph}$, it was determined that few vehicles were travelling over $35 \mathrm{mph}$ throughout school zone crashes despite North Carolina having no statewide school zone speed limit. In addition, out of the 1,023 crashes in North Carolina from 2006 - 2010, only 129 involved speeds over $50 \mathrm{mph}$. The posted speed limit along roadways involving school zone crashes ranges from under $20 \mathrm{mph}$ to $70 \mathrm{mph}$, with majority $(66.57 \%)$ of speed limits between 25 and $35 \mathrm{mph}$ as shown in Table 4.2-4. Even with only one posted speed limit less than $20 \mathrm{mph}$, the mean speed limit is only $40 \mathrm{mph}$. Vehicle speed is independent of driver gender, with males tending to drive slightly but insignificantly faster. Urban freeways and urban multilane divided non-freeways had the highest posted speed limits ranging from 55 to $70 \mathrm{mph}$.

Table 4.2-4: North Carolina Speed Limit Frequency

\begin{tabular}{|l|r|r|}
\hline \multicolumn{3}{|c|}{ Speed Limit of Road } \\
\hline Speed Limit & Frequency & $\begin{array}{c}\text { Relative } \\
\text { Frequency }\end{array}$ \\
\hline$<20 \mathrm{mph}$ & 1 & $0.10 \%$ \\
\hline $25-35 \mathrm{mph}$ & 681 & $66.57 \%$ \\
\hline $40-50 \mathrm{mph}$ & 158 & $15.44 \%$ \\
\hline $55-65 \mathrm{mph}$ & 135 & $13.20 \%$ \\
\hline $70 \mathrm{mph}$ & 48 & $4.69 \%$ \\
\hline
\end{tabular}

Most common type of vehicle involved in school zone crashes in North Carolina is passenger car followed by pickup truck then SUV. There were very few other types of vehicles, including bikers and pedestrians. A relatively equal number of male and female drivers were involved in crashes, with slightly more males than females; however there were 1,784 drivers and only 816 
passengers involved in school zone crashes. This indicates one of two things: that most crashes occur either after parents have dropped their children off or before they have picked them up; or that crashes involve drivers who are using the school zone as a thru-way route not to access the school. In either case it can be concluded that drivers operate more safely when passengers are present in the vehicle, and in the case of school zone crashes, parents, in particular, driver safer when children are passengers.

Table 4.2-5: North Carolina Crash Severity Frequency

\begin{tabular}{|l|r|r|}
\hline \multicolumn{2}{|c|}{ Crash Severity } \\
\hline Severity & Frequency & Relative \\
& & Frequency \\
\hline Fatal Injury & 11 & $1.08 \%$ \\
\hline Injury & 308 & $30.11 \%$ \\
\hline No Injury & 678 & $66.28 \%$ \\
\hline Unknown & 26 & $2.54 \%$ \\
\hline
\end{tabular}

Table 4.2-6 shows that occupant age ranges from 1 to 999 , with a mean of 47 years and median of 31 years, indicating that most occupants are drivers. The most frequent age rand is $16-20$ years old which makes sense due to student drivers being inexperienced. Children under 15 are involved in the least amount of crashes of any age range. Most occupants, regardless of age or gender, use proper safety restraint including shoulder and lap belt which led to majority of crashes resulting in no injury as shown in Table 4.2-5. 
Table 4.2-6: North Carolina Descriptive Statistics

\begin{tabular}{|l|r|r|r|r|}
\hline & \multicolumn{1}{|c|}{ Vehicle Speed } & Posted Speed Limit & Number of Vehicles & Occupant Age \\
\hline Min & 0 & 0 & 1 & 1 \\
\hline 1st Qu. & 10 & 35 & 2 & 18 \\
\hline Median & 30 & 35 & 2 & 31 \\
\hline Mean & 27.28 & 40.69 & 1.816 & 47.43 \\
\hline 3rd Qu. & 35 & 45 & 2 & 48 \\
\hline Max & 100 & 70 & 4 & 999 \\
\hline Variance & NA & & 95.94641 & 0.281263 \\
\hline Std. Dev. & NA & 9.795224 & 0.530342 & $\mathrm{NA}$ \\
\hline
\end{tabular}

Driver pre-crash actions were mostly straight ahead movements and slowing in traffic which most frequently resulted in collision with moving motor vehicle. $66 \%$ of crashes resulted in no injury, with only $30 \%$ resulting in injury and only $1 \%$ involving fatalities. Most crashes were two-vehicle rear-end crashes $(32 \%)$ with only property damage, due to slow vehicle speeds and the stop-and-go nature of the drop-off and pick-up areas of school zones. Run-off-road, angle and left-hand turn crashes all experienced similar frequencies at around 15\%. Crash type seems to be independent of time of day. Across all hours of the day, most crashes were rear-end, with before and after school hours involving more run-off-road crashes than any other type. The number of vehicles involved in a crash ranged from one to four, with mean, median and third quartile of two. The amount of two vehicle crashes is almost double the amount if single vehicle crashes, while crashes with three or more vehicles were very uncommon.

Crashes have remained around 200 per year, with the highest being 229 in 2006 and the lowest being 178 in 2008. There were 204 in 2010, the most recent year of data collected. All crash counts were between 175 and 230 per year, occurring most often during after school activities from 4:00 pm to 7:00 pm. A similar number of crashes occurred during school hours from 9:00 am to 2:00 pm, while very few crashes occur before or after school hours. 
Most school zone crashes occurred along urban two lane roads with no special design features. Driveway access and intersection related crashes occurred at the same frequency and nonintersection crashes were the least common. Very few rural roads experienced school zone crashes, and all crashes along rural roads were single vehicle.

The majority of vehicles involved in crashes in school zones in North Carolina are traveling below $35 \mathrm{mph}$. Even in cases with posted speed limits of $65 \mathrm{mph}$, cars are travelling at low speeds. This speed distribution is occurring despite North Carolina having no statewide school zone speed limit statute. While traversing through school zones, motorists innately drive slower and lowering school zone speed limits is an unnecessary attempt to reduce school zone crashes since it was found in this data set that vehicle speed is not the main contributing factor to school zone crashes.

\section{3: Comparison}

The results from the HSIS data analysis were compatible across Ohio and North Carolina. Without corresponding data from West Virginia, comparisons are merely speculations, but due to the similar nature of school zone issues across the United States, many findings are applicable. In terms of demographics, Ohio and North Carolina are relatively comparable to West Virginia area-wise; however, population in Ohio and North Carolina is much greater than in West Virginia, as is indicated by Table 4.3-1. 
Table 4.3-1: State Demographics

\begin{tabular}{|c|c|c|c|}
\hline & Ohio & $\begin{array}{c}\text { North } \\
\text { Carolina }\end{array}$ & $\begin{array}{c}\text { West } \\
\text { Virginia }\end{array}$ \\
\hline $\begin{array}{c}\text { Area } \\
\text { (sq. mi.) }\end{array}$ & $\begin{array}{c}34 \text { th in U.S. } \\
44,825\end{array}$ & $\begin{array}{c}28 \text { th in U.S. } \\
53,819\end{array}$ & $\begin{array}{c}41 \text { st in U.S. } \\
24,230\end{array}$ \\
\hline Population & $\begin{array}{c}7 \text { th in U.S. } \\
11,544,225\end{array}$ & $\begin{array}{c}10 \text { th in U.S. } \\
9,752,073\end{array}$ & $\begin{array}{c}38 \text { th in U.S. } \\
1,855,413\end{array}$ \\
\hline $\begin{array}{c}\text { Population } \\
\text { Density }\end{array}$ & $\begin{array}{c}10 \text { th in U.S. } \\
\text { 282/sq. mi. }\end{array}$ & $\begin{array}{c}15 \text { th in U.S. } \\
\text { 200.2/sq. mi. }\end{array}$ & $\begin{array}{c}29 \text { th in U.S. } \\
77.1 / \text { sq. mi. }\end{array}$ \\
\hline $\begin{array}{c}\text { Largest } \\
\text { Metro }\end{array}$ & $\begin{array}{c}\text { Cleveland or } \\
\text { Cincinnati }\end{array}$ & Charlotte & Charleston \\
\hline
\end{tabular}

The main differences between Ohio, North Carolina, and West Virginia school zones are the school zone speed limits. In Ohio, the maximum speed limit is $65 \mathrm{mph}$ on certain interstate and state freeways, and rural highways. The minimum speed limit is $15 \mathrm{mph}$ (prima facie speed limit) on alleys within a municipal corporation, and school zones are $20 \mathrm{mph}$ (prima facie) during recess or when children are going to be leaving school. Based on geometric and traffic characteristics studies, the state or local governments may increase or decrease these limits on any highway. Local governments must either request or obtain State approval for any speed limit changes on the streets or highways within their jurisdictions. In North Carolina the maximum speed limit is $70 \mathrm{mph}$ on the interstate highway system or other controlled access highways. Local authorities may post lower speed limits than provided on school property subject to the approval of governing body. The Board of Transportation or a local government may establish speed limits in designated school zones. These limits are in effect when school is in session. Such a limit cannot be less than $20 \mathrm{mph}$. The minimum speed limit in West Virginia is $55 \mathrm{mph}$ on open country highways, controlled access highways and interstate highways. The law provides that the speed limit "shall not be less than" $55 \mathrm{mph}$ for controlled access and interstate 
highways (or $65 \mathrm{mph}$ where posted). The school zone speed limit is $15 \mathrm{mph}$ and is in effect "during school recess or while children are going to or leaving school during opening or closing hours." Based on engineering and traffic investigations, a local government may decrease the above speed limits at intersections. If the speed alteration by a local government applies to a State highway or an extension thereof, such alteration must be approved by the Commissioner of Highways.

In regards to the HSIS data analysis in Ohio and North Carolina, the main differences were the number of school zone crashes and the occurrence of eleven fatalities in North Carolina compared to zero in Ohio. Distribution of crashes per year by state is shown in Table 4.3-2. Despite the statewide school zone speed limit of $20 \mathrm{mph}$ in Ohio compared to no statewide school zone speed limit in North Carolina and the higher crash frequency in North Carolina, both states had only eleven crashes involving a motor vehicle striking a pedestrian/bicyclist.

Table 4.3-2: HSIS Crash Frequency per State

\begin{tabular}{|c|c|c|}
\hline \multicolumn{3}{|c|}{ Number of School Zone Crashes per State per Year } \\
\hline & \multicolumn{2}{|c|}{ State } \\
\hline Year & Ohio & North Carolina \\
\hline $\mathbf{2 0 0 6}$ & 149 & 228 \\
\hline $\mathbf{2 0 0 7}$ & 157 & 190 \\
\hline $\mathbf{2 0 0 8}$ & 117 & 177 \\
\hline $\mathbf{2 0 0 9}$ & 117 & 220 \\
\hline $\mathbf{2 0 1 0}$ & 102 & 203 \\
\hline
\end{tabular}

The majority of fatalities in North Carolina from 2006 - 2010 occurred on urban multi-lane divided non-freeways. Only $27 \%$ of all school zone crashes occurred on this type of roadway, indicating that fatal crashes have different attributes than the typical school zone crash. While urban multi-lane undivided non-freeways had the highest fatality rate, the highest injury rate was 
on urban two-lane roads. Also of note is that in the instance of a fatality, most occupants were not using any safety restraint.

$72 \%$ of fatal crashes were single vehicle crashes, while $64 \%$ of all school zone crashes involved two vehicles. No fatal crashes occurred in 2010, the most recent year of data collected. In 2006, 2007, and 2009 there were 3 fatal crashes. 2006 also had the highest injury rate among crashes. Half of all fatalities occurred during school hours (9:00 am - 1:59 pm) while majority of crashes (28\%) occur during after school activities $(4: 00 \mathrm{pm}-7: 59 \mathrm{pm})$ which is also when majority of injury crashes occur. Since North Carolina has no statewide school zone speed limit, the speed limit in school zones throughout the state varies by school site. Majority of fatalities $(63.64 \%)$ occurred on roads with speed limit 55 - $65 \mathrm{mph}$; whereas majority $(65.58 \%)$ of injury crashes occurred on roads with speed limit $25-35 \mathrm{mph}$.

Based on these findings, it can be determined that the occurrence of fatal crashes in North Carolina is the result of driver behavior rather than general school zone operations. Typical school zone crashes result from very different pre-crash actions and under different circumstances than fatal crashes. The number of vehicles, time of day, roadway type, and many other factors vary greatly between school zone crashes and school zone fatalities in North Carolina.

\section{4: Summary of Findings}

The cause of school zone crashes in Ohio and North Carolina is not the action typically associated with school zone crashes: vehicle speed. Even in North Carolina, where there is not designated statewide school zone speed limit, vehicle speed at the time of a crash is around 20 mph. It is also of note that majority of crashes occurred when driver was alone in the vehicle, and very few instances involved bikers or pedestrians. It is evident that drivers are more aware of 
their actions in terms of safety when children are present. In terms of standards, specifications, policies, and procedures, school zone safety and efficiency incentives should target driver awareness, so that they are operating safely with or without children visibly present. When drivers understand that their actions impact student safety whether they see the repercussions or not, school zone safety will improve. 
Through an extensive literature review and supporting data analysis, there were some recurring trends in the study of school zone traffic flow operations. Safety is the primary concern associated with school zones, and vehicle speed is typically the main target. While managing vehicle speed is an important component of school zone safety, it is often poorly conveyed to drivers. Drivers are aware that they need to be traveling at low speeds in the presence of children; however, they are unaware of their actual speeds throughout school zones. Drivers need feedback regarding their speed performance throughout school zones. Majority of crashes occur when school zone speeds are in effect, which indicates that drivers are apt to forget that they are in a school zone. While findings also found that vehicle speed is not a major contributing factor in school zone crashes, drivers still need feedback regarding performance since vehicle speed is the main focus of safety initiatives within school zones and feedback serves as a reminder to drivers of their presence within a school zone. Most school zone crashes are rear-end crashes, indicating that driver inattention and congestion are the main contributing factors.

Student mode choice is also an important component of school zone operations. Vehicle mix and mode choice contribute to both safety and efficiency. The presence of pedestrians serves as a visual reminder to drivers that children are present, causing them to drive more cautiously, and the shift of students walking rather than arriving in private vehicles eases congestion and improves the efficiency of a school zone. Unfortunately, mode choice is more commonly associated with efficiency and congestion is not the mission of many schools. A lack of incentives and awareness on the impact of efficiency on safety and their reliance on each other leads mode choice to be neglected. 
The best way to achieve speed compliance in school zones is to target driver perception and awareness. While drivers are aware that the presence of children indicates lower speed, they are often unaware of their actual speed. Responsive traffic control devices, which provide feedback to drivers on their speed, are worthwhile investments in addressing vehicle speed and driver performance.

Reducing congestion is best attained through an incentive and awareness program. Since congestion is not the focus of many schools, targets should be set for schools to reduce auto use. Incentives for reaching these targets should be provided. Congestion reduction is best achieved through a unique combination of programs to address the issues of individual sites. Each issue should have alternate programs for implementation and should be handled uniformly upon application. Congestion can also be addressed through traffic flow design and increased law enforcement.

The best way to address traffic issues in school zones is to attack safety and efficiency with a singular solution. Emphasizing mode choice is a cost-effective way to affect both safety and efficiency. Shifting student mode choice from private vehicle to walking can impact safety by reducing the frequency of private vehicles and the occurrence of crashes; on the other hand, mode choice can impact efficiency by reducing congestion and vehicle mix within school zones. Public awareness campaigns are the best way to introduce the public to these issues.

The best way to implement successful, long lasting changes in school zone operations is through uniformity, public awareness, and multidisciplinary cooperation. Public awareness campaigns encompass all of these elements and are already in effect through various national campaigns, such as Safe Routes to School. Safe Routes to School targets students within walking distance; 
however, walkability within West Virginia school zones is often unattainable. In those instances, multimodal options could be implemented. Multimodal options are implemented by identifying a specific number of bus stops and organizing walking school buses. By gathering students within a defined walkable area to one bus stop, the amount of school buses and congestion can be reduced. This is especially beneficial in counties that are struggling to fund the amount of bus routes required by current school zone traffic operations.

The implementation of these programs is best handled through a combination of various disciplines. Getting input and cooperation from school administrators, law enforcement officials, traffic engineers and community members ensures that all aspects of an issue are addressed before, during and after program implementation. The goal of these programs should be to address public concerns by adapting to driver behavior and creating incentives.

The amount of students within walking distance to school in West Virginia may not be a justifiable number of students to target in shifting mode choice. Initiatives should be made to encourage students to ride the bus and deter parents from transporting their children to and from school. Improving the reliability, accessibility and convenience of bus routes throughout West Virginia could be the most practical way to reduce congestion and improve safety within West Virginia.

While safety initiatives often target only vehicle speed, through the analysis of this report it was determined that vehicle speed is not a major contributing factor in school zone crashes; therefore, vehicle speed alone should not be the focus of school zone safety programs. While West Virginia crash data was unavailable for this study, the consistencies among results from the states analyzed leads to the conclusion that school zone crashes remain consistent regardless of crash 
location. In addition, the limited occurrence of pedestrian related crashes, leads to the conclusion that vehicle speed is not the dominating issue concerning school zones. Instead, it is recommended that school zone operations should acknowledge the dependency of efficiency and safety on one another. The best way to achieve this is through education of all personnel associated with school zones ranging from parents and students to traffic engineers. If all facets of school zone operations are committed to the same goals of a school zone and understand the importance of these goals, only then will school zones operate at the highest level of safety and efficiency. 
Anderson, R. W. G.; McLean, A. J.; Farmer, M. J. B.; Lee, B. H.; and Brooks, C. G. (1997). Vehicle travel speeds and the incidence of fatal pedestrian crashes. Accident Analysis and Prevention, $667-674$.

Beck, L.F.; Greenspan, A. I. (2008). Why don't more children walk to school? Journal of Safety Research, 449 - 452.

Cambridge Systematics, Inc. with Kittleson and Associates, Inc. (2009, June) Study of school zones with traffic signals. Florida Department of Transportation Office of Traffic Operations, 75 pages.

Carlson, Daniel; Gruen, Deric; Thacker, Jennifer. (2009, Jan). Transportation demand strategies for schools, phase II reporting: reducing auto congestion around schools. Washington State Transportation Commission.

Cen ters for Disease Control and Prevention. (2002, Aug). Barriers to children walking and biking to school. MMWK Weekly, 1 - 6.

Crowe, Rebecca; Rivas, Raquel G.; Watts, Kathy Norcross. (2009, Aug). Safe routes to school: making a big difference via small steps. Public Roads, 4.

Fitzpatrick, Kay; Brewer, Marcus A., and Park, Eun Sug. (2010). Suggestions concerning school traffic control devices. Transportation Research Board: Journal of the Transportation Research Board, No. 2149, 1 - 10.

Harre, N. (2003). Discrepancy between actual and estimated speeds of drivers in the presence of child pedestrians.Injury Prevention, 38 - 41.

Hawkins, H. Gene, Jr. (2007, June). Rear-facing school speed limit beacons. Institute of Transportaiton Engineers, ITE Journal, 18.

Isebrands, Hillary N; Hallmark, Shauna L. (2007, Mar). School zone safety and operational problems at existing elementary schools. Institute of Transportaiton Engineers, ITE Journal, 26.

Jenner, Sergeant Denny; Hare, Officer John. (1999). School zone traffic management 2000. Submission for: 1999 Herman Goldstein Award for Excellence in Problem-Oriented Policing.

Kweon, Byoung-Suk; Shin, Woo-Hwa; Folzenlogen, Robert; Kim, Jun-Hyun. (2006, Sept). Children and transportation: identifying environments that foster walking and biking to school. Texas Transportation Institute; Research Report, 1 - 37. 
Lee, Choulki; Lee, Sangsoo; Choi, Bongsoo; Oh, Youngtae. (2006). Effectiveness of speedmonitoring displays in speed reduction in school zones. Transportation Research Record:Journal of the Transportation Research Board, No. 1973, 27 - 35.

McDonald, Noreen. (2005). Children's travel: patterns and influences. Dissertation; Doctor of Philosophy in City and Regional Planning in the Graduate Division of the University of California, Berkeley, 1 - 112.

McDonald, Noreen C.; Aalborg, Annette E. (2009). Why parents drive children to school: implications for safe routes to school programs. Journal of the American Planning Association, 331 - 342.

Nors, Officer Alicia S. (2004). Easing traffic congestion around barron early childhood school. Plano Police Department, Neighborhood Police Officer Unit.

Parisi, David; Hondorp, Brett. (2005, Mar). Transportation professionals get involved with safe routes to school. Institute of Transportaiton Engineers, ITE Journal, 41.

Rodriguez, D.; Joo, J. (2004). The relationship between non-motorized mode choice and the local physical environment. Transportation Research, 151 - 173.

Saibel, Charlie; Salzberg, Philip; Doane, Richard; Moffat, John. (1999, Nov). Vehicle speeds in school zones. Institute of Transportaiton Engineers, ITE Journal, 38.

Saito, Mitsuru; Ash, Kelly. (2005, June). Evaulation of four recent traffic safety initiatives, Volume IV: Increasing speed limit compliance in reduced speed school zones. Brigham Young University, Civil and Environmental Engineering for Utah Department of Transportation; Final Report, 159.

Schrader, Michael H. Study of effectiveness of selected school zone traffic control devices. Paper; Committee of Traffic Control Devices.

Simpson, Carrie L. (2008). Evaluation of effectiveness of school zone flashers in North Carolina. Transportation Research Record: Journal of the Transportation Research Board, No. 2074, 21 - 28.

Tay, Richard. (2000, May). Speed compliance in school and playground zones. Institute of Transportaiton Engineers, ITE Journal, 36.

U.S. Department of Transportation; National Highway Traffic Safety Administration. Automated speed enforcement in school zones in Portland, Oregon. Traffic TechTechnology Transfer Series.

West Virginia Department of Transportation. "School Area Traffic Control." Traffic Engineering Directive 701-2. WV: Division of Highways, August 14, 2003. 5. 
West Virginia Department of Transportation. "Warning Sign Location and Sight Distance Criteria." Traffic Engineering Directive 201. WV: Division of Highways, April 13, 1994. 5.

West Virginia Legislature. "Traffic Regulations and Laws of the Code." West Virginia Code. Chapter 17C. 2011.

Winters, Richard H. (2011). Reliability and validity of the Safe Routes to School parent and student surveys. International Journal of Behavioral Nutrition \& Physical Activity. 56 63.

Wells, Leslie; Shapiro, Richard; Felsberg, Robert (1977 Aug). Schools located near highways: problems and prospects. Report; Marshall Kaplan, Gans, and Kahn, Alan M. Vorhees and Associates for Federal Highway Administration, Department of Transportation, 468.

Woolridge, Mark; Cooner, Scott; Fitzpatrick, Kay. (2003, July). Transportation concerns near schools. $2^{\text {nd }}$ Urban Street Symposium (Anaheim, California).

Young, Elizabeth; Dixon, Karen. The effects of school zones on driver behavior. Georgia Institute of Technology; School of Civil and Environmental Engineering. 
1. What are the three most important school zone traffic safety issues within your county?

\begin{tabular}{|c|c|}
\hline Speeding & traffic sign violation \\
\hline Congestion & pedestrian safety \\
\hline Traffic law enforcement & traffic flow design \\
\hline Arrival/dismissal procedure awareness & vehicle mix \\
\hline Inclement weather & emergency/disaster procedures \\
\hline
\end{tabular}

2. Rank the following in order of most influence on school zone traffic flow and safety procedures within the county.

_ County superintendent

- Parents

_ $\quad$ School principal

L Law enforcement official

_ County transportation director

(Other)

3. Assign an approximate percentage to the following in terms of most prevalent form of student transport to and from school.

Private vehicle where student is driver

Private vehicle where student is passenger

Walking

School bus

Biking

4. In establishing school zones and traffic patterns, how do you apply the following parameters?

\section{Speed limit}




\section{Length of zone}

Age of students (elementary, middle, high school)

School location (neighborhood, secluded campus)

Number of access points to school property

Vehicle mix

5. Rate the following potential improvements to school zone safety from 1 to 4 (4 being most important.) Specify what improvements only for those assigned highest value.

Reduced speed

Increased penalties for traffic violations within school zones (specify what penalties)

Uniformity in school zone procedures throughout the county (specify what procedures)

Public awareness campaigns (specify types of campaigns) 
Gary Price, Superintendent; Marion County

1. What are the three most important school zone traffic safety issues within your county?

\begin{tabular}{|c|c|c|c|}
\hline & Speeding & & traffic sign violation \\
\hline \multirow[t]{2}{*}{$\mathrm{X}$} & Congestion & & pedestrian safety \\
\hline & Traffic law enforcement & $\mathrm{X}$ & traffic flow design \\
\hline \multirow[t]{3}{*}{$\mathrm{X}$} & Arrival/dismissal procedure awareness & & vehicle mix \\
\hline & Inclement weather & & emergency/disaster procedures \\
\hline & Location & & \\
\hline
\end{tabular}

2. Rank the following in order of most influence on school zone traffic flow and safety procedures within the county.

5 County superintendent

2 Parents

1 School principal

3 Law enforcement official

4 County transportation director

(Other)

3. Assign an approximate percentage to the following in terms of most prevalent form of student transport to and from school.

$2 \% \quad$ Private vehicle where student is driver

$12 \%$ Private vehicle where student is passenger

$5 \%$ Walking

$\underline{80 \%}$ School bus

$1 \% \quad$ Biking

4. In establishing school zones and traffic patterns, how do you apply the following parameters?

\section{Speed limit}

State code 


\section{Length of zone}

State code and WVDE policy

Age of students (elementary, middle, high school)

All the same

School location (neighborhood, secluded campus)

Determined by state code

\section{Number of access points to school property}

All treated same

\section{Vehicle mix}

Attempt to keep parent/teacher vehicles separate from buses

5. Rate the following potential improvements to school zone safety from 1 to 4 (4 being most important.) Specify what improvements only for those assigned highest value.

1 Reduced speed

1 Increased penalties for traffic violations within school zones (specify what penalties)

2 Uniformity in school zone procedures throughout the county (specify what procedures)

2 Public awareness campaigns (specify types of campaigns) 
Gary Watson; Supervisor of Transportation; Raleigh County

1. What are the three most important school zone traffic safety issues within your county?

\begin{tabular}{llll}
$\frac{\mathrm{X}}{\mathrm{X}}$ & Speeding & & traffic sign violation \\
& Congestion & $\mathrm{X}$ & pedestrian safety \\
& Traffic law enforcement & & traffic flow design \\
& $\begin{array}{l}\text { Arrival/dismissal procedure awareness } \\
\text { Inclement weather } \\
\text { Location }\end{array}$ & - & vehicle mix \\
\hline & - & emergency/disaster procedures
\end{tabular}

2. Rank the following in order of most influence on school zone traffic flow and safety procedures within the county.

4 County superintendent

2 Parents

3 School principal

1 Law enforcement official

5 County transportation director

6 (Other) District Manager/Engineer

3. Assign an approximate percentage to the following in terms of most prevalent form of student transport to and from school.

$15 \%$ Private vehicle where student is driver

$34 \%$ Private vehicle where student is passenger

$1 \%$ Walking

$\underline{50 \%} \quad$ School bus

$\underline{0 \%}$ Biking

4. In establishing school zones and traffic patterns, how do you apply the following parameters?

\section{Speed limit}

\section{Length of zone}


Age of students (elementary, middle, high school)

School location (neighborhood, secluded campus)

Number of access points to school property

Vehicle mix

5. Rate the following potential improvements to school zone safety from 1 to 4 (4 being most important.) Specify what improvements only for those assigned highest value.

Reduced speed

Increased penalties for traffic violations within school zones (specify what penalties)

Uniformity in school zone procedures throughout the county (specify what procedures)

Public awareness campaigns (specify types of campaigns) 
Lew Maze; Director of Transportation; Pleasants County

1. What are the three most important school zone traffic safety issues within your county?

$\begin{array}{llll}\mathrm{X} & \begin{array}{l}\text { Speeding } \\ \text { Congestion }\end{array} & - & \text { traffic sign violation } \\ & \text { pedestrian safety } \\ \overline{\mathrm{X}} & \begin{array}{l}\text { Traffic law enforcement } \\ \text { Arrival/dismissal procedure awareness }\end{array} & & \text { traffic flow design } \\ \mathrm{X} & \begin{array}{l}\text { Inclement weather } \\ \text { Location }\end{array} & & \text { vehicle mix } \\ & & & \text { emergency/disaster procedures }\end{array}$

2. Rank the following in order of most influence on school zone traffic flow and safety procedures within the county.
County superintendent
Parents
School principal
__ Law enforcement official
1 County transportation director
2 (Other) Board of Education

3. Assign an approximate percentage to the following in terms of most prevalent form of student transport to and from school.

$10 \%$ Private vehicle where student is driver

$20 \%$ Private vehicle where student is passenger

Walking

70\% School bus

Biking

4. In establishing school zones and traffic patterns, how do you apply the following parameters?

Speed limit

\section{Length of zone}


Age of students (elementary, middle, high school)

School location (neighborhood, secluded campus)

Number of access points to school property

Vehicle mix

5. Rate the following potential improvements to school zone safety from 1 to 4 (4 being most important.) Specify what improvements only for those assigned highest value.

1 Reduced speed

Increased penalties for traffic violations within school zones (specify what penalties)

2 Uniformity in school zone procedures throughout the county (specify what procedures)

Parent flyers, student practice walk-throughs, loading/unloading zone patterns, especially bus vs. private vehicle routes.

3 Public awareness campaigns (specify types of campaigns)

$\underline{\text { Similar to uniformity. Better awareness }=\text { better compliance }}$ 
Sherry Dean; Transportation Director; Upshur County

1. What are the three most important school zone traffic safety issues within your county?

$\begin{array}{ll}- & \text { Speeding } \\ & \text { Congestion } \\ & \text { Traffic law enforcement } \\ \square & \text { Arrival/dismissal procedure awareness } \\ & \text { Inclement weather } \\ & \text { Location }\end{array}$

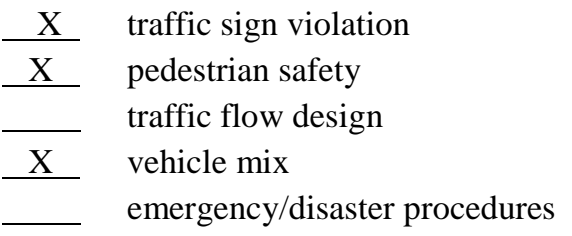

2. Rank the following in order of most influence on school zone traffic flow and safety procedures within the county.

$\begin{array}{ll} & \text { County superintendent } \\ - & \text { Parents } \\ -2 & \text { School principal } \\ -\quad \text { Law enforcement official } \\ +\quad \text { County transportation director } \\ \end{array}$

3. Assign an approximate percentage to the following in terms of most prevalent form of student transport to and from school.

4\% Private vehicle where student is driver

$10 \%$ Private vehicle where student is passenger

$\leq 1 \% \quad$ Walking

$\underline{86 \%}$ School bus

$\underline{0 \%}$ Biking

4. In establishing school zones and traffic patterns, how do you apply the following parameters?

Speed limit

Length of zone 
Determined by amount of buses using it at one time and how much we have to work with.

\section{Age of students (elementary, middle, high school)}

Same as above

\section{School location (neighborhood, secluded campus)}

It is done the same county-wide regardless of location. Our schools have ample room for loading/ unloading zones.

\section{Number of access points to school property}

\section{Vehicle mix}

We do not want the mix, it is dangerous. We have established parent drop-offs/pick-ups away from loading/unloading zone.

5. Rate the following potential improvements to school zone safety from 1 to 4 (4 being most important.) Specify what improvements only for those assigned highest value.

\section{- Reduced speed}

Speed is always $15 \mathrm{mph}$. This is fine IF OBEYED.

Increased penalties for traffic violations within school zones (specify what penalties)

They do not need to be increased; they need to be enforced.

Uniformity in school zone procedures throughout the county (specify what procedures)

It is uniform throughout county, but principals need to make sure that parents stay out of the loading zone

They have a designated pick-up and drop-off area. They need to stay in it and not mix with buses

Public awareness campaigns (specify types of campaigns)

We have used public newspaper, school newsletter, and county website. 
Charlie Tribble; Coordinator of Transportation; Putnam County

1. What are the three most important school zone traffic safety issues within your county?

\begin{tabular}{ll}
\hline $\mathrm{X} \quad$ & Speeding \\
& Congestion \\
& Traffic law enforcement \\
& Arrival/dismissal procedure awareness \\
& Inclement weather \\
& Location
\end{tabular}

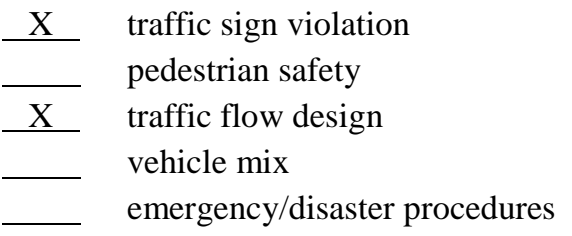

2. Rank the following in order of most influence on school zone traffic flow and safety procedures within the county.

1 County superintendent

Parents

$2 \quad$ School principal

L_ Law enforcement official

3 County transportation director

(Other)

3. Assign an approximate percentage to the following in terms of most prevalent form of student transport to and from school.

$13 \%$ Private vehicle where student is driver

$20 \%$ Private vehicle where student is passenger

$2 \% \quad$ Walking

$65 \%$ School bus

Biking

4. In establishing school zones and traffic patterns, how do you apply the following parameters?

\section{Speed limit}

$\underline{\text { State required } 15 \mathrm{mph}}$

\section{Length of zone}


Determined by entry/exit points and any crosswalks

\section{Age of students (elementary, middle, high school)}

$\underline{\text { Same for all }}$

\section{School location (neighborhood, secluded campus)}

$\underline{\text { Same for all }}$

\section{Number of access points to school property}

Main entry/exit - schools are bordered by fence

\section{Vehicle mix}

Most have separate drop-off points for parent drop and school buses.

5. Rate the following potential improvements to school zone safety from 1 to 4 (4 being most important.) Specify what improvements only for those assigned highest value.

$3 \quad$ Reduced speed

$4 \quad$ Increased penalties for traffic violations within school zones (specify what penalties)

Magistrate court determines penalty

3 Uniformity in school zone procedures throughout the county (specify what procedures)

4 Public awareness campaigns (specify types of campaigns)

Public announcement 
Vicki Hinerman; Superintendent; Summers County

1. What are the three most important school zone traffic safety issues within your county?

\begin{tabular}{llll}
\hline $\mathrm{X}$ & $\begin{array}{l}\text { Speeding } \\
\text { Congestion }\end{array}$ & & traffic sign violation \\
& Traffic law enforcement & pedestrian safety \\
& Arrival/dismissal procedure awareness & traffic flow design \\
Inclement weather & - & vehicle mix \\
Location & - & emergency/disaster procedures \\
\hline
\end{tabular}

2. Rank the following in order of most influence on school zone traffic flow and safety procedures within the county.

4 County superintendent

5 Parents

3 School principal

2 Law enforcement official

1 County transportation director

(Other)

3. Assign an approximate percentage to the following in terms of most prevalent form of student transport to and from school.

$14 \%$ Private vehicle where student is driver

$25 \%$ Private vehicle where student is passenger

$\underline{1 \%}$ Walking

$60 \%$ School bus

Biking

4. In establishing school zones and traffic patterns, how do you apply the following parameters?

Speed limit

Varies according to location

\section{Length of zone}


Age of students (elementary, middle, high school)

$\underline{\text { Varies according to location }}$

\section{School location (neighborhood, secluded campus)}

Varies according to location

\section{Number of access points to school property}

Varies according to location

\section{Vehicle mix}

Varies according to location

5. Rate the following potential improvements to school zone safety from 1 to 4 (4 being most important.) Specify what improvements only for those assigned highest value.

\section{Reduced speed}

Increased penalties for traffic violations within school zones (specify what penalties)

Uniformity in school zone procedures throughout the county (specify what procedures)

3 Public awareness campaigns (specify types of campaigns) 
Robin Daquilante; Superintendent; Tyler County

1. What are the three most important school zone traffic safety issues within your county?

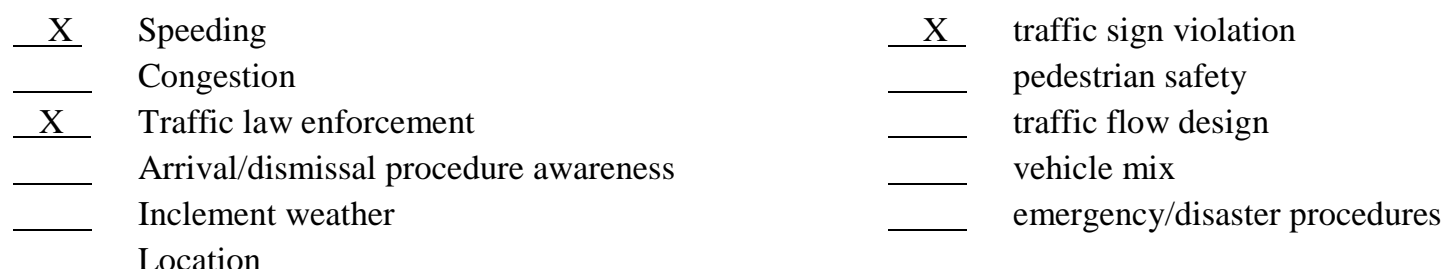

2. Rank the following in order of most influence on school zone traffic flow and safety procedures within the county.

4 County superintendent

5 Parents

3 School principal

1 Law enforcement official

2 County transportation director

(Other)

3. Assign an approximate percentage to the following in terms of most prevalent form of student transport to and from school.

$13 \%$ Private vehicle where student is driver

$7 \%$ Private vehicle where student is passenger

$\underline{0 \%} \quad$ Walking

$\underline{80 \%} \quad$ School bus

$\underline{0 \%}$ Biking

4. In establishing school zones and traffic patterns, how do you apply the following parameters?

Speed limit

Always $15 \mathrm{mph}$

\section{Length of zone}


Age of students (elementary, middle, high school)

$\underline{\text { Same regardless of level }}$

\section{School location (neighborhood, secluded campus)}

All rural campuses

\section{Number of access points to school property}

All access points are school zones

\section{Vehicle mix}

Applies to all

5. Rate the following potential improvements to school zone safety from 1 to 4 (4 being most important.) Specify what improvements only for those assigned highest value.

\section{Reduced speed}

2 Increased penalties for traffic violations within school zones (specify what penalties)

3 Uniformity in school zone procedures throughout the county (specify what procedures)

$4 \quad$ Public awareness campaigns (specify types of campaigns) 
Irv Schuetzner; Director of Transportation and Ancillary Services; Monongalia

1. What are the three most important school zone traffic safety issues within your county?

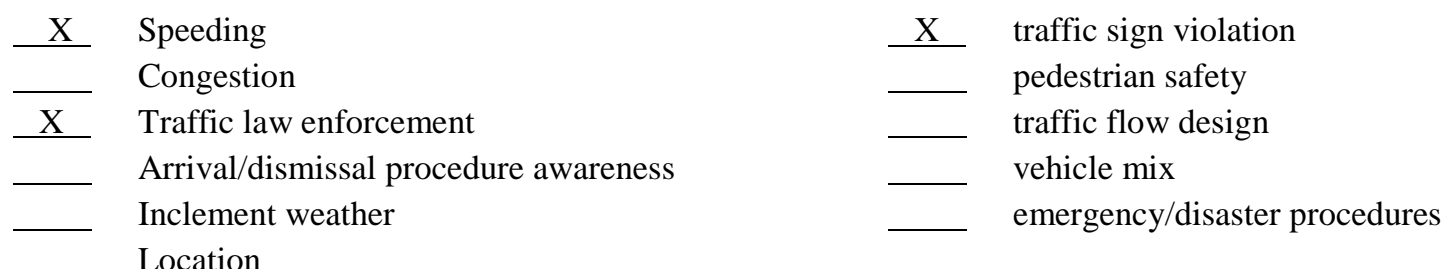

2. Rank the following in order of most influence on school zone traffic flow and safety procedures within the county.

4 County superintendent

5 Parents

$6 \quad$ School principal

2 Law enforcement official

3 County transportation director

1 (Other) Bus drivers

3. Assign an approximate percentage to the following in terms of most prevalent form of student transport to and from school.

6\% Private vehicle where student is driver

$12 \%$ Private vehicle where student is passenger

$\underline{1 \%}$ Walking

$\underline{80 \%} \quad$ School bus

$1 \%$ Biking

4. In establishing school zones and traffic patterns, how do you apply the following parameters?

\section{Speed limit}

$\underline{\text { State and federal DOT code }}$

\section{Length of zone}


$\underline{\text { State and federal DOT code }}$

Age of students (elementary, middle, high school)

$\underline{\text { State and federal DOT code }}$

School location (neighborhood, secluded campus)

$\underline{\text { State and federal DOT code }}$

\section{Number of access points to school property}

$\underline{\text { State and federal DOT code }}$

\section{Vehicle mix}

$\underline{\text { State and federal DOT code }}$

5. Rate the following potential improvements to school zone safety from 1 to 4 (4 being most important.) Specify what improvements only for those assigned highest value.

1 Reduced speed

2 Increased penalties for traffic violations within school zones (specify what penalties)

3 Uniformity in school zone procedures throughout the county (specify what procedures)

4 Public awareness campaigns (specify types of campaigns) 
Barbara Whitecotton; Superintendent; Hardy County

1. What are the three most important school zone traffic safety issues within your county?

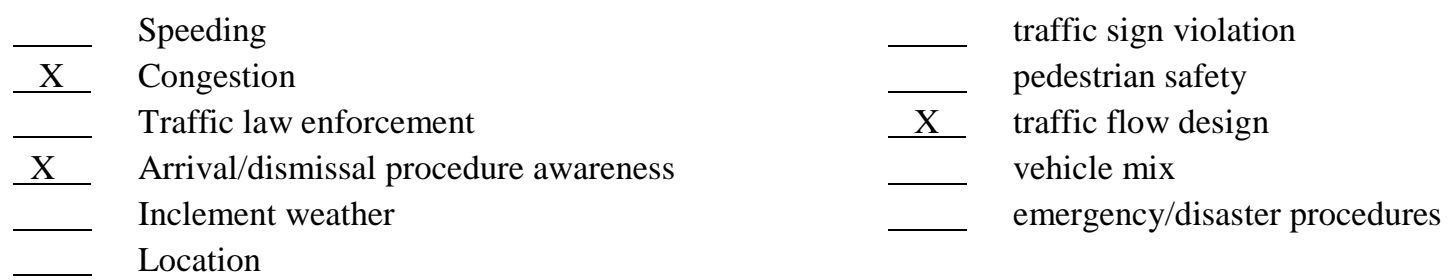

2. Rank the following in order of most influence on school zone traffic flow and safety procedures within the county.

5 County superintendent

4 Parents

2 School principal

1 Law enforcement official

3 County transportation director

(Other)

3. Assign an approximate percentage to the following in terms of most prevalent form of student transport to and from school.

$10 \%$ Private vehicle where student is driver

$28 \%$ Private vehicle where student is passenger

$\underline{2 \%} \quad$ Walking

$60 \%$ School bus

Biking

4. In establishing school zones and traffic patterns, how do you apply the following parameters?

Speed limit

Established by law enforcement and monitored by them and followed by school system

\section{Length of zone}


Determined by the speed limit as well as the entrances, exits and size of facilities

\section{Age of students (elementary, middle, high school)}

Elementary: closely monitored by staff with separate loading areas for parent pick-up and bus pickups.

Middle and high schools are monitored for safety with more flexibility in parent pick up.

\section{School location (neighborhood, secluded campus)}

\section{Number of access points to school property}

\section{Vehicle mix}

5. Rate the following potential improvements to school zone safety from 1 to 4 (4 being most important.) Specify what improvements only for those assigned highest value.

Reduced speed

Increased penalties for traffic violations within school zones (specify what penalties)

Uniformity in school zone procedures throughout the county (specify what procedures)

Public awareness campaigns (specify types of campaigns) 
Mike Hammer; Safety Coordinator; Pendleton

1. What are the three most important school zone traffic safety issues within your county?

$\begin{array}{llll}\mathrm{X} & \begin{array}{l}\text { Speeding } \\ \text { Congestion }\end{array} & & \text { traffic sign violation } \\ & \text { Traffic law enforcement } & \text { pedestrian safety } \\ & \text { Arrival/dismissal procedure awareness } & \mathrm{X} & \text { traffic flow design } \\ & \text { Inclement weather } & & \text { vehicle mix } \\ \text { Location } & - & \text { emergency/disaster procedures }\end{array}$

2. Rank the following in order of most influence on school zone traffic flow and safety procedures within the county.

1 County superintendent

- Parents

- School principal

__ Law enforcement official

County transportation director

2 (Other) Board of Education

3. Assign an approximate percentage to the following in terms of most prevalent form of student transport to and from school.

$10 \%$ Private vehicle where student is driver

$5 \%$ Private vehicle where student is passenger

$\underline{5 \%} \quad$ Walking

$\underline{80 \%}$ School bus

— Biking

4. In establishing school zones and traffic patterns, how do you apply the following parameters?

Speed limit

Established by state law. Monitored periodically by sheriff department. Flashing lights.

\section{Length of zone}


Depends on site. Not monitored by county.

\section{Age of students (elementary, middle, high school)}

More speeding at high school. More pedestrians at elementary.

\section{School location (neighborhood, secluded campus)}

One elementary school, away from major through fare and no flashing lights there. Pre-determined locations. Adapt to location as problems arise.

\section{Number of access points to school property}

Depends on site. Not changed once established.

\section{Vehicle mix}

Flashing lights as warnings. Police for enforcement/flow enforcement.

5. Rate the following potential improvements to school zone safety from 1 to 4 (4 being most important.) Specify what improvements only for those assigned highest value.

$1 \quad$ Reduced speed

2 Increased penalties for traffic violations within school zones (specify what penalties)

Fine for speeding

Uniformity in school zone procedures throughout the county (specify what procedures)

Public awareness campaigns (specify types of campaigns) 


\section{Dave Weekly; Cabell County}

1. What are the three most important school zone traffic safety issues within your county?

\begin{tabular}{|c|c|c|c|}
\hline T & Speeding & & traffic sign violation \\
\hline $\mathrm{X}$ & Congestion & & pedestrian safety \\
\hline & Traffic law enforcement & $\mathrm{X}$ & traffic flow design \\
\hline $\mathrm{X}$ & Arrival/dismissal procedure awareness & $\mathrm{X}$ & vehicle mix \\
\hline & Inclement weather & & emergency/disaster procedures \\
\hline
\end{tabular}

2. Rank the following in order of most influence on school zone traffic flow and safety procedures within the county.

\begin{tabular}{ll}
- & County superintendent \\
- & Parents \\
\hline 2 & School principal \\
-3 & Law enforcement official \\
1 & County transportation director
\end{tabular}

(Other)

3. Assign an approximate percentage to the following in terms of most prevalent form of student transport to and from school.

$15 \%$ Private vehicle where student is driver

$25 \%$ Private vehicle where student is passenger

Walking

$60 \%$ School bus

_ Biking

4. In establishing school zones and traffic patterns, how do you apply the following parameters?

\section{Speed limit}

As defined in WV state laws

\section{Length of zone}




\section{Age of students (elementary, middle, high school)}

Younger - more supervision/crossing guards. Elementary within town limits so more pedestrians.

\section{School location (neighborhood, secluded campus)}

Elementary schools - older built before traffic flow was an issue. Newer Middle/High School site picked With traffic flow at least thought about.

\section{Number of access points to school property}

Dependent on school location

\section{Vehicle mix}

Memos to parents. Reminders in paper to watch for stopped buses. Verbal discussion with parents on proper pick-up/drop-off to prevent delay of traffic flow. Also if needed discussions with local law.

5. Rate the following potential improvements to school zone safety from 1 to 4 (4 being most important.) Specify what improvements only for those assigned highest value.

\footnotetext{
Reduced speed

2 Increased penalties for traffic violations within school zones (specify what penalties)
}

$\underline{\text { Passing school buses increased penalty }}$

Uniformity in school zone procedures throughout the county (specify what procedures)

1 Public awareness campaigns (specify types of campaigns)

Awareness of congestion and importance of obeying safety laws and proper procedures. 
Alice Irvine; Associate Superintendent; Pocahontas County

1. What are the three most important school zone traffic safety issues within your county?

\begin{tabular}{llll}
$\mathrm{X}$ & Speeding & $\mathrm{X}$ & traffic sign violation \\
& Congestion & & pedestrian safety \\
$\mathrm{X}$ & Traffic law enforcement & traffic flow design \\
& $\begin{array}{l}\text { Arrival/dismissal procedure awareness } \\
\text { Inclement weather } \\
\text { Location }\end{array}$ & - & vehicle mix \\
\hline & - & emergency/disaster procedures
\end{tabular}

2. Rank the following in order of most influence on school zone traffic flow and safety procedures within the county.

\begin{tabular}{ll}
- & County superintendent \\
- & Parents \\
$\frac{1}{4}$ & School principal \\
$\frac{4}{2}$ & Law enforcement official \\
\hline & County transportation director \\
3 & (Other) Bus operators
\end{tabular}

3. Assign an approximate percentage to the following in terms of most prevalent form of student transport to and from school.

5\% Private vehicle where student is driver

$15 \%$ Private vehicle where student is passenger

Walking

$\underline{80 \%}$ School bus

Biking

4. In establishing school zones and traffic patterns, how do you apply the following parameters?

Speed limit

WV law/design specifications

\section{Length of zone}


WV law/design specifications

Age of students (elementary, middle, high school)

Each school has own procedures. Varies by site.

\section{School location (neighborhood, secluded campus)}

Design specifications

\section{Number of access points to school property}

Design specifications

\section{Vehicle mix}

$\underline{\text { Traffic violations dealt with by law enforcement and sometimes parent involvement. }}$

5. Rate the following potential improvements to school zone safety from 1 to 4 (4 being most important.) Specify what improvements only for those assigned highest value.

- Reduced speed

2 Increased penalties for traffic violations within school zones (specify what penalties)

$\underline{\text { Traffic sign violations biggest issue. Increase fine? }}$

1 Uniformity in school zone procedures throughout the county (specify what procedures)

Currently varies by school site. Overall uniformity.

Public awareness campaigns (specify types of campaigns) 
Manoo Saidi; Traffic Engineer; District 1

1. What are the three most important school zone traffic safety issues within your district?

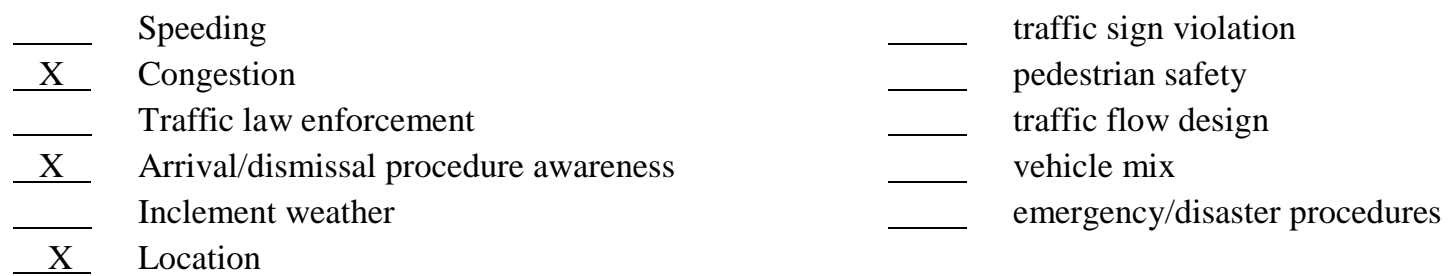

2. Rank the following in order of most influence on school zone traffic flow and safety procedures within the district.

4 County superintendent

3 Parents

2 School principal

5 Law enforcement official

1 County transportation director

6 (Other) District Manager/Engineer

3. Assign an approximate percentage to the following in terms of most prevalent form of student transport to and from school.

$10 \%$ Private vehicle where student is driver

$30 \%$ Private vehicle where student is passenger

$\underline{0 \%} \quad$ Walking

$60 \%$ School bus

$\underline{0 \%} \quad$ Biking

4. In establishing school zones and traffic patterns, how do you apply the following parameters?

Speed limit

Length of zone 
Age of students (elementary, middle, high school)

School location (neighborhood, secluded campus)

Number of access points to school property

Vehicle mix

5. Rate the following potential improvements to school zone safety from 1 to 4 (4 being most important.) Specify what improvements only for those assigned highest value.

1 Reduced speed

1 Increased penalties for traffic violations within school zones (specify what penalties)

1 Uniformity in school zone procedures throughout the county (specify what procedures)

1 Public awareness campaigns (specify types of campaigns) 
Ismail Latif; District Traffic Engineer; District 7

1. What are the three most important school zone traffic safety issues within your county?

\begin{tabular}{|c|c|c|c|}
\hline \multirow{2}{*}{$\mathrm{X}$} & Speeding & & \multirow{2}{*}{ traffic sign violation } \\
\hline & Congestion & $\mathrm{X}$ & \\
\hline$X$ & Traffic law enforcement & & traffic flow design \\
\hline & Arrival/dismissal procedure awareness & & vehicle mix \\
\hline & Inclement weather & & emergency/disaster procedures \\
\hline
\end{tabular}

2. Rank the following in order of most influence on school zone traffic flow and safety procedures within the county.

1 County superintendent

$6 \quad$ Parents

5 School principal

4 Law enforcement official

2 County transportation director

3 (Other) District Manager/Engineer

3. Assign an approximate percentage to the following in terms of most prevalent form of student transport to and from school.

$10 \%$ Private vehicle where student is driver

$35 \%$ Private vehicle where student is passenger

$\underline{3 \%} \quad$ Walking

$50 \% \quad$ School bus

$\underline{2 \%}$ Biking

4. In establishing school zones and traffic patterns, how do you apply the following parameters?

Speed limit

Speed limit is assessed when children are present. It is usually $15 \mathrm{mph}$. Speed limit is assessed when

Children are not present based on $85^{\text {th }}$ percentile speed

\section{Length of zone}


The length of zone is assessed 500 feet beyond school premises.

\section{Age of students (elementary, middle, high school)}

Parameter not used.

\section{School location (neighborhood, secluded campus)}

School zones are established only if children are dropped by parents and school buses on the highway. If

$\underline{\text { School has its own access road, the school zone may not be needed. }}$

\section{Number of access points to school property}

Could influence length of school zone.

\section{Vehicle mix}

Parameter not used

5. Rate the following potential improvements to school zone safety from 1 to 4 (4 being most important.) Specify what improvements only for those assigned highest value.

\section{$4 \quad$ Reduced speed}

3 Increased penalties for traffic violations within school zones (specify what penalties)

1 Uniformity in school zone procedures throughout the county (specify what procedures)

2 Public awareness campaigns (specify types of campaigns) 
Dave Burris; Traffic Engineer; District 3

6. What are the three most important school zone traffic safety issues within your disrict?

\begin{tabular}{llll}
\hline $\mathrm{X}$ & $\begin{array}{l}\text { Speeding } \\
\mathrm{X}\end{array}$ Congestion & $\mathrm{X}$ & traffic sign violation \\
\hline & $\begin{array}{l}\text { Traffic law enforcement } \\
\text { Arrival/dismissal procedure awareness }\end{array}$ & & pedestrian safety \\
& & traffic flow design \\
Inclement weather & - & vehicle mix \\
Location & - & emergency/disaster procedures
\end{tabular}

7. Rank the following in order of most influence on school zone traffic flow and safety procedures within the district.

5 County superintendent

$6 \quad$ Parents

$4 \quad$ School principal

3 Law enforcement official

2 County transportation director

1 (Other) District Manager/Engineer

8. Assign an approximate percentage to the following in terms of most prevalent form of student transport to and from school.

$20 \%$ Private vehicle where student is driver

$30 \%$ Private vehicle where student is passenger

$\underline{10 \%}$ Walking

$40 \% \quad$ School bus

$\underline{0-1 \%}$ Biking

9. In establishing school zones and traffic patterns, how do you apply the following parameters?

Speed limit

Standard school zone $15 \mathrm{mph}$ speed limit is used; as allowed by statute.

\section{Length of zone}


By statute, maximum length can only be as much as abutting length of school property to respective

$\underline{\text { Roadway, plus an additional } 125 \text { feet on each end of abutting length. }}$

\section{Age of students (elementary, middle, high school)}

No extra preference is given to establishment of a school zone based on age.

\section{School location (neighborhood, secluded campus)}

Could determine where and/or if crosswalks are installed, in order to accommodate kids that walk to $\underline{\text { School. }}$

\section{Number of access points to school property}

No special provisions made in response to access points to school.

\section{Vehicle mix}

$\underline{\text { Same as above }}$

10. Rate the following potential improvements to school zone safety from 1 to 4 (4 being most important.) Specify what improvements only for those assigned highest value.

\section{Reduced speed}

Increase police presence in school zones where speeding is an issue.

2 Increased penalties for traffic violations within school zones (specify what penalties)

3 Uniformity in school zone procedures throughout the county (specify what procedures)

Many schools have antiquated school zone signing, pavement markings, and flashers which need updated.

2 Public awareness campaigns (specify types of campaigns) 